\title{
Monetary Policy and Long-Run Systemic Risk-Taking
}

\author{
Gilbert Colletaz $^{1} \quad$ Grégory Levieuge ${ }^{2}$
}

\section{Alexandra Popescu ${ }^{3}$}

\author{
September 2018, WP \#694
}

\begin{abstract}
As an extension to the literature on the risk-taking channel of monetary policy, this paper studies the existence of a systemic risk-taking channel (SRTC) in the Eurozone, through an original macroeconomic perspective based on causality measures. Because the SRTC is effective after an "incubation period", we make a distinction between short and long-term causality, following the methodology proposed by Dufour and Taamouti (2010). We find that causality from monetary policy to systemic risk, while not significant in the very short term, robustly represents 75 to $100 \%$ of the total dependence between the two variables in the long run. Reverse causality is rejected: systemic risk did not influence the policy of the European Central Bank before the global financial crisis. However, central banks must be aware that a too loose monetary policy stance may be conducive to a build-up of systemic risk.
\end{abstract}

Keywords: Monetary Policy, Systemic Risk-Taking, Long Run Causality, SRisk JEL classification: E52 ; E58 ; G21

\footnotetext{
${ }^{1}$ Univ. Orléans, CNRS, LEO, UMR 7322, F-45067, France.

${ }^{2}$ Corresponding author. Banque de France, DGEI-DEMFI-RECFIN (041-1391); 31, rue Croix des Petits Champs, 75049 Paris Cedex 01 France. Email: gregory.levieuge@banque-france.fr, and Univ. Orléans, CNRS, LEO, UMR 7322, F-45067, France.

${ }^{3}$ Univ. Poitiers, CRIEF, 2, rue Jean Carbonnier, 86073 Poitiers, France.

We are grateful to Annual INFER and AFSE conference participants as well as seminar participants at the Banque de France for their remarks and comments. Furthermore we thank Christophe Hurlin for his valuable suggestions and Eric Jondeau for the data on SRisk. Any remaining errors are ours.

Working Papers reflect the opinions of the authors and do not necessarily express the views of the Banque de France. This document is available on publications.banque-france.fr/en
} 


\section{NON-TECHNICAL SUMMARY}

According to the "Risk-Taking Channel" (RTC) proned by many economists, keeping key interest rates "too low, too long" would alter risk perception and risk tolerance. Therefore, the global financial crisis could be at least partly explained by the risky behaviour of financial companies during the pre-crisis period, fuelled by the context of low interest rates, for a protracted period of time.

As an extension to this literature, the objective of this paper is to study the existence of a systemic risk-taking channel (SRTC) in the Eurozone. Our contribution is original in four aspects.

First, while the traditional literature on the RTC mainly refers to "risk" as a liquidity or default risk, we focus on systemic risk, considering that risky activities and positions may spread from banks to the entire financial system. This echoes a new generation of theoretical models that demonstrate how low interest rates environment are conducive to endogenous build-up of systemic risk. Second, we adopt a macroeconomic perspective, while the majority of the empirical studies are performed on bank-level data. Third, we search for evidence supporting the SRTC in terms of causality from monetary policy to systemic risk. Last, as the SRTC assumes that key interest rates have been too low for "too long", we explicitly consider a long-term perspective. Indeed, the impact of monetary policy on systemic risk, if any, may not be immediate but effective after an "incubation period". Basically, a protracted period of easy monetary policy is likely to impact risk tolerance and risk perception, which in turn will have a negative impact on the systemic risk-taking, through an insidious degradation of financial companies' balance sheets.

Long-term causality from monetary policy to systemic risk-taking

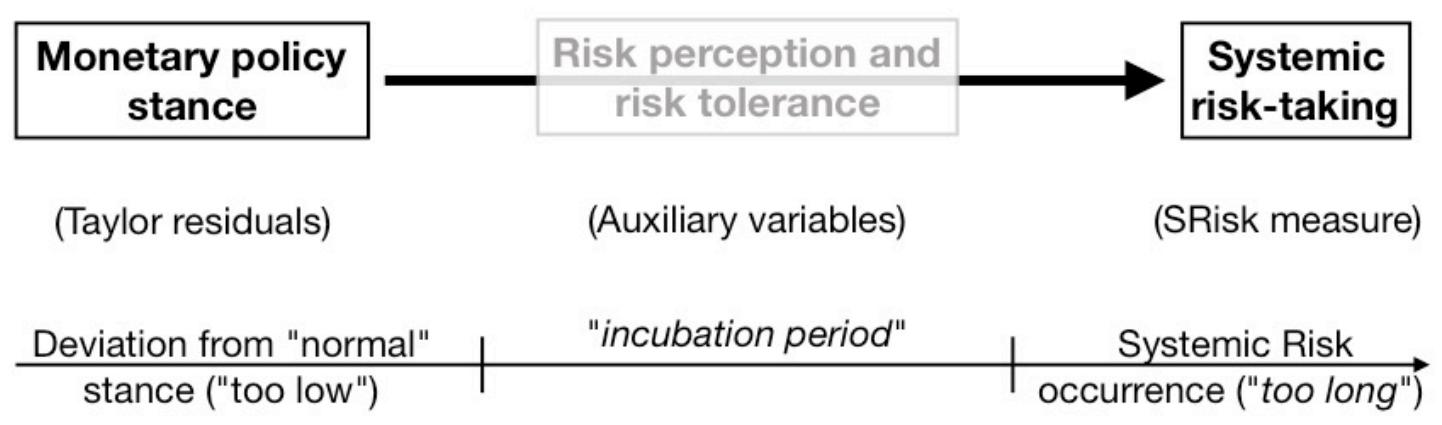

Our empirical analysis thus relies on a long-term causality approach. Following the graphical representation above, this consists of testing the causality of the monetary stance to the systemic risk-taking through various auxiliary variables aimed at capturing risk tolerance and risk perception.

We use monthly data over the period 2000M1 - 2008M4. Our baseline measure of the monetary policy stance is based on the deviation of actual interest rates from a benchmark 
defined by a Taylor-type rule ("Taylor residuals"). The systemic risk is captured by the aggregate SRisk measure. Basically, this measure represents the total amount of capital that would be needed to bail out the financial system if a financial crisis were to occur. This measure of systemic risk has proven to be relevant and provides fair early warning signals of on-going financial distress. Finally, auxiliary variables are made of alternative proxies accounting for the global risk perception, the perception of firms' riskiness and the perception of banks' riskiness.

In most cases, we find causality from monetary policy to systemic risk to represent 75 to $100 \%$ of the total dependence between the two variables in the long run, even though it does not appear significant in the very short term. This validates the existence of a SRTC in the Eurozone on the eve of the global financial crisis.

Causality from systemic risk to the monetary policy stance is also estimated. Our results show no such causal relationship in this direction. This is not surprising as financial stability was not an objective per se for most of the central banks before 2008. Until recently, policymakers could not even rely on reliable indicators of risk, such as the Srisk measure. Finally, central banks must be aware that a too loose monetary policy stance, for a protracted period of time, may be conducive to negative externalities such as the progressive build-up up of systemic risk.

\section{Politique monétaire et prise de risque systémique à long terme}

\section{RÉSUMÉ}

Dans la lignée de la littérature sur le canal de la prise de risque, cet article vise à tester empiriquement l'existence d'un canal de prise de risque systémique en zone euro au cours de la période précédant la crise financière de 2008. A cette fin, nous nous appuyons sur des mesures de causalité. Dans la mesure où la manifestation de ce canal requiert une période d'incubation, nous employons une méthodologie proposée par Dufour \& Taamouti (2010), permettant de tester l'existence de causalité à court, mais aussi à long terme. Nous trouvons que la politique monétaire cause significativement le risque systémique à long terme. Ce sens de causalité représente 75 à 100\% de la relation de dépendance entre politique monétaire et risque systémique. En revanche, la causalité inverse est rejetée. Ainsi, les banques centrales doivent avoir conscience qu'une orientation accommodante, pendant une longue période, tend à favoriser la montée du risque systémique.

Mots-clés : Politique monétaire, Prise de risque systémique, causalité de long terme, SRisk.

Les Documents de travail reflètent les idées personnelles de leurs auteurs et n'expriment pas nécessairement la position de la Banque de France. Ils sont disponibles sur publications.banque-france.fr 


\section{Introduction}

A lot of studies investigated the causes of the outbreak and the severity of the Global Financial Crisis (GFC). Many of them focused on the responsibility of monetary policy (Acharya and Richardson, 2009; Allen and Carletti, 2009; Diamond and Rajan, 2009) and assert that the pre-crisis context of low interest rates for a protracted period of time $(2002-2006)$ and low inflation, accompanied by an abundance of global liquidity, would have led financial companies to behave in a riskier way. In this respect, Borio and Zhu (2012) defined the underlying risktaking channel (RTC) of monetary policy as "the impact of changes in policy rates on either risk perceptions or risk-tolerance and hence on the degree of risk in the portfolios, on the pricing of assets, and on the price and non-price terms of the extension of funding". ${ }^{\text {Some central }}$ bankers have already embraced the results of this literature and explicitly refer to the RTC to disapprove of what they consider as a too loose monetary policy. ${ }^{2}$

As an extension to this literature, the objective of this paper is to study the existence of a systemic risk-taking channel (SRTC) in the Eurozone. Our contribution is original in four respects.

First, as risky activities and positions may spread from banks to the entire financial system, our focus is on systemic risk. ${ }^{3}$ In the empirical literature on the RTC, risk mainly refers to liquidity or default risk. Systemic risk is neglected, although according to the recent survey of Benoit et al. (2017), the mechanisms behind the RTC underlie an even more serious problem, which is systemic risk-taking. Benoit et al. (2017) define it as the fact that "financial institutions choose to be exposed to similar risks and take large risk exposures, thus reinforcing amplification mechanisms, exposing themselves to default and their counterparts to contagion". As a source of systemic risk (along with contagion and amplification mechanisms), systemic risk-taking is an important concern for policymakers and academics. In this respect, a new generation of models with financial frictions proposed by Brunnermeier and Sannikov (2014), He and Krishnamurthy (2014) and Dewachter and Wouters (2014) demonstrate how low interest rates

\footnotetext{
${ }^{1}$ Similar ideas were formulated by Fisher (1933), Hayek (1939) or Kindleberger (1978).

${ }^{2}$ See for instance the Minutes of the Federal Open Market Committee, April 26-27, 2016, p.10. See also Bernanke (2013).

${ }^{3}$ Systemic risk is defined by Benoit et al. (2017) as "the risk that many market participants are simultaneously affected by severe losses, which then spread through the system".
} 
and low-risk environments are conducive to endogenous build-up of systemic risk. Thus, in this paper, we evaluate such a potential adverse effect of monetary policy on one of the most reliable systemic risk measure, namely the aggregate SRisk indicator (Acharya et al., 2012; Brownlees and Engle, 2016). The aggregate SRisk, defined as the total amount of capital that would be needed to bail out the financial system conditional on a financial crisis, is particularly suitable to our research objective as besides being able to detect sudden shifts in systemic risk-taking, it also gives a better view of how risk really evolved before the outbreak of the financial crisis.

Second, in keeping with the previous point, we adopt a macroeconomic perspective. The majority of the empirical studies are performed on bank-level data. But evidence of risk-taking at the microeconomic level does not necessarily imply significant macroeconomic effects (Bonfim and Soares, 2014), a fortiori if, as asserted by Dell'Ariccia et al. (2017), the economic magnitude of microeconomic effects is rather small. Moreover, while the literature mainly focuses on credit risk, policy rates may affect the overall balance sheet of economic agents, which in turn impact global risk, with uncertain macroeconomic and systemic effects. Yet, macroeconomic evidence on this matter is very scarce. We fill this gap by studying the existence of the SRTC at the euro area level using aggregate data on the monetary policy stance and the systemic risk.

Third, we search for evidence supporting the SRTC in terms of Granger causality from monetary policy to risk. The RTC is usually gauged in the light of impulse response functions (IRFs) of risk measures to a one-period monetary policy shock. However, Dufour and Tessier (1993) demonstrate that the nullity of impulse response functions is a condition that is neither necessary nor sufficient to conclude to the Granger non-causality between two variables when a third variable (or vector) is included. Therefore, in such a trivariate scenario, analyses based on IRFs are insufficient to conclude whether one variable causes (or not) another one. To our knowledge, none of the existing studies treats the RTC from a Granger causality point of view.

Last, we explicitly consider a long-term perspective. Indeed, the impact of monetary policy on systemic risk, if any, is not immediate but effective after an "incubation period". Our empirical approach relies on long-term causality as defined by Dufour and Renault (1998): a variable $x$ causes another variable $y$ at horizon $h$ if the past of $x$ improves the prediction of $y$ 
for the horizon $t+h .{ }^{4}$ Then, the rationale for the method we use in this paper is the following: even if $x$ may not Granger causes $y$ (in the short run), causality from $x$ to $y$ may exist through an auxiliary variable $z$, such that $x$ causes $z$, which in turn causes $y$, at a longer horizon $t+h$. The auxiliary variables are supposed to capture the (mis)perception of risk and the underlying insidious financial imbalances which are conducive to the build-up of systemic risk in the long run. Such a long-term perspective is largely ignored in the literature.

We thus provide an extension to the literature on the RTC, by offering new evidence with an original approach, both in terms of methodology and risk measure. We find that causality from monetary policy to systemic risk is rejected according to the usual "short term" Granger and Geweke causality measures, but at longer horizons this causality seems to hold. More precisely, the long-run causality from monetary policy to systemic risk robustly represents 75 to $100 \%$ of the total dependence between the two variables. On the contrary, reverse causality is not significant. This confirms the fact that, before the crisis, systemic risk did not influence the stance of the European Central Bank (ECB). However, according to our results, central banks must be aware that a too loose monetary policy stance, like in the 2000s, may be conducive to a build-up of systemic risk. This remains an important topic even today, given that monetary policy has been very accommodating in many countries for nearly ten years now.

The rest of the paper is structured as follows. Section 2 summarizes the main theoretical and empirical results obtained in the literature on the risk-taking channel, underlying the flaws of this literature and how we deal with them in this study. In Section 3, we describe the methodology and in Section 4, we present our main results. We perform a robustness analysis in Section 5 and Section 6 concludes.

\section{Literature Review}

This section aims at reviewing the main theoretical and empirical developments related to the RTC. Furthermore, it presents the way in which our contribution deals with the limitations of the existing literature.

\footnotetext{
${ }^{4}$ By contrast, standard Geweke and Granger causality tests deal with "short term" causality, in that they gauge whether $x$ improves the prediction of $y$ for the period $t+1$ only.
} 


\subsection{The theoretical foundations of the systemic risk-taking channel}

A comprehensive review of the literature indicates that the RTC is a combination of four inextricable mechanisms. First of all, traditional portfolio allocation models predict a negative link between real interest rates and banks' risk-taking. Indeed, a low risk-free rate induces a substitution from safer assets to riskier ones. This increases the riskiness of banks' portfolios.

Second, a related mechanism operates through the "search for yield" hypothesis, according to which financial institutions tend to engage in risky investments to earn excess returns in a low interest rate environment (Brunnermeier, 2001; Rajan, 2006). This effect is reinforced when financial institutions have target rates of return established in nominal terms. Moreover, it is exacerbated by the bonus scheme and the herding behavior arising when managers are evaluated vis-à-vis their peers.

Third, the RTC relies on the moral hazard created by past policies. Given that long periods of favorable economic outcomes and good news lead banks and investors to underestimate risks (Gennaioli et al., 2015; Thakor, 2015), effective policies encouraged risk-taking and compressed risk premiums (Borio and Zhu, 2012). In addition to this "paradox of credibility view", past experiences of bail out produce an insurance effect which also encourages risk-taking (Cao and Illing, 2015; Diamond and Rajan, 2009, 2012; Farhi and Tirole, 2012).

Fourth, firms' and banks' balance sheet effects are essential to understanding how risk perception and tolerance lead gradually and insidiously to systemic risk. The literature on the financial accelerator and on the bank capital channel ${ }^{5}$ explain why and how lending increases and the cost of financing decreases following a reduction in interest rates. However, new loans are not necessarily riskier, because balance sheets are stronger and collateral is higher. ${ }^{6}$ Therefore, default rates and leverage ratios are supposed to decrease following interest rate cuts. Quality of credit (as opposed to quantity) and risk attitude are both neglected.

Nevertheless, recent contributions show that lower risk-free rates imply a lower hurdle rate

\footnotetext{
${ }^{5}$ See for example Gertler and Karadi (2011), Holmstrom and Tirole (1997) or Levieuge (2009).

6 Typically, banks operating under limited liability and asymmetric information have incentives to take excessive risk, since they do not internalize the potential losses incurred by their creditors. But bank capital reduces such an agency problem. As a "skin-in-the-game" effect, the more the bank has to lose in case of failure, the more it will monitor its portfolio and invest cautiously. So, an interest rate cut increases the intermediation spread (whenever the aggregate demand for loans is negatively sloped), the value of banks' assets and future profits. This implies less moral hazard and less risk-taking.
} 
for risky investment projects (Chodorow-Reich, 2014) and may reduce banks' screening incentives (Dell'Ariccia and Marquez, 2006). Thus, borrowers with bad credit histories and more vague projects may benefit from higher risk tolerance, which insidiously deteriorates the quality of the banks' balance sheet. Typically, by reformulating the standard Costly State Verification (CSV) contract that is central in Bernanke et al. (1999), Afanasyeva and Güntner (2016) demonstrate that it is optimal for a profit-maximizing bank to respond to an expansionary policy shock by lending more relative to borrowers' collateral (i.e. tolerating lower credit standards), even if this raises firms' leverage ratios (as in Adrian and Shin, 2009) and default rates (as in Gonzàles-Aguado and Suarez, 2015). ${ }^{7}$

Similarly, the recent literature on risk-shifting indicates that an accommodating interest rate policy "sows the seeds for the next crisis", by facilitating the financing of unworthy projects (Farhi and Tirole, 2012) and by worsening the misperception of risk (Dubecq et al., 2015). ${ }^{8}$ Additional evidence, at the halfway between risk-shifting mechanisms and the bank capital channel, is provided by Dell'Ariccia et al. (2014) and Valencia (2014). While the latter unambiguously supports the RTC, the former find that risk-taking depends on the capitalization (or, equivalently, leverage) of banks.

The liability side of banks' balance sheet is also influenced by monetary policy. Gertler et al. (2012) and Angeloni et al. (2015) show that an expansionary monetary policy induces banks to increase their risk exposure by choosing a more leveraged and less capitalized structure. Furthermore, as the probability of bank run is low in such a context, banks can more easily issue debt in order to grant riskier loans (Diamond and Rajan, 2006).

Finally, as an extension of this literature, a new generation of models with financial frictions demonstrate how low interest rates and low-risk environments are conducive to greater endogenous build-up of systemic risk (Brunnermeier and Sannikov, 2014; Challe et al., 2013; Dewachter and Wouters, 2014). In their comprehensive survey, Benoit et al. (2017) precisely stress that the mechanisms behind the RTC underlie systemic risk.

\footnotetext{
${ }^{7}$ In particular, given the need for some firms to rely on retained earnings in order to reduce leverage, it is easier for them to adjust leverage up, in case of interest rate cuts, than down in case of an interest rate rise. See Molina (2005) for instance for an assessment of the effect of leverage on default risk.

8 See for example Hau and Lai (2016) for empirical evidence on risk-shifting from money to riskier equity markets when real interest rates decrease.
} 
All in all, misperception of banks and firms' riskiness increases systemic risk through the latent and gradual degradation of their balance sheets when the interest rates are too low too long. Against this consensus, Cociuba et al. (2016) are rather skeptical. Certainly, low policy rates reduce the returns on safe assets and lead banks to shift investments towards riskier assets (portfolio effect). But, given fewer bond purchases, banks have less collateral available for repo market transactions. This collateral effect constrains their ability to take more risk. According to Drees et al. (2013), the link between interest rates and risk-taking is ambiguous, depending on the sources of risk.

\subsection{Empirical evidence}

Empirical evidence on RTC mainly relies on micro-survey data. They differ by the way they identify risk-taking. Various variables are used: banks' expected default frequencies (Altunbas et al., 2014; Gambacorta, 2009; Gambacorta and Marques-Ibañez, 2011), the proportion of risk assets and the ratio of non-performing loans (Delis and Kouretas, 2011), loan default probabilities deduced from firm-bankruptcy data and corporate loan spreads (Delis et al., 2017), rating of loans based on the confidential individual loan-level data from the Federal Reserve's Survey of Terms of Business Lending - STBL - (Dell'Ariccia et al., 2017), measures of risk tolerance based on bank lending surveys (De Nicolo et al., 2010; Paligorova and Santos, 2017). All of these studies validate the RTC in the U.S. and in European countries. Moreover, in accordance with the aforementioned banks' balance sheet effects, some studies point out that the impact of interest rates on risk-taking depends on banks' capital (Delis and Kouretas, 2011; Delis et al., 2017; Jiménez et al., 2014) and mainly concerns those banks that are more prone to agency problems (Ioannidou et al., 2015).

However, micro-level evidence does not necessarily imply significant global effects. We observe that macroeconomic studies are scarce. They mainly rely on VAR models where the RTC is gauged by the yardstick of impulse responses of a measure of risk to a one-period interest rate shock. Different measures of risks are used, such as the VIX index (Bekaert et al., 2013), the stock of private debt, or the volatility of a bank equity index (Angeloni et al., 2015). Buch et al. (2014) and Maddaloni and Peydro (2011) use alternative methods, i.e. respectively 
a factor-augmented autoregressive model exploiting the information provided by the Federal Reserve's STBL on the riskiness of banks' new loans, and a panel data analysis based on the informational content of bank lending surveys. All these studies conclude that monetary policy robustly influences risks by changing both the banks' funding structure and the riskiness of their assets.

While rather convincing, these studies share common limits. First, while recent theoretical developments indicate that the RTC is conducive to systemic risk (Benoit et al., 2017), the empirical literature only deals with liquidity or default risks. Moreover, they do not duly consider the fact that the build-up of risk is a long process. Typically, evaluating the "too low for too long" effect of monetary policy by a response to a one-period interest rate shock is inadequate. The theoretical foundations of the SRTC involve mechanisms that have effects after an "incubation period". Moreover, they do not test causality from monetary policy to risk.

In this paper, we precisely search for evidence supporting the SRTC at the macroeconomic level for the euro area, in terms of short and long-run causalities from monetary policy to systemic risk. The next section describes the framework used to compute these measures.

\section{Measures of long-run causality}

Our method relies on long-run causality measures provided by Dufour and Taamouti (2010). When referring to long-run causality hereafter we follow the definition given by Dufour and Renault (1998): a variable $x$ causes another variable $y$ at horizon $h$ if the past of $x$ improves the prediction of $y$ for the horizon $t+h$. By contrast, the famous measures suggested by Geweke (1982), as well as the Granger causality tests, deal with "short term" causality, in that they gauge whether $x$ improves the prediction of $y$ for the period $t+1$ only. Then, the rationale for the method we use in this paper, based on Dufour and Taamouti (2010), is the following: $x$ may not Granger cause $y$, but indirect, long-run causality, from $x$ to $y$ may exist through an auxiliary variable $z$, such that $x$ causes $z$, which in turn causes $y$. As a consequence, the absence of Granger causality, or equivalently, the absence of causality at horizon 1, does not preclude causality at longer horizons. 
This concept of "long-run" causality is particularly suitable to our research question, as the impact of monetary policy on systemic risk is not immediate. Indeed, the SRTC is supposed to be effective after an "incubation period", through different channels and mechanisms which may precisely be captured by the auxiliary variables $z$.

The long-run causality measures suggested by Dufour and Taamouti (2010) are based on a $\operatorname{VAR}(\mathrm{p})$ model, with at least three variables. In our models, $x$ will represent the monetary policy stance, $y$ the systemic risk and $z$ will include all the auxiliary variables through which monetary policy may transit to influence systemic risk and vice versa. Basically, these auxiliary variables are indicators of perceived risk and are based on firms and banks' balance sheet structures (see next section for details on data). Noting $W=\left(x^{\prime}, y^{\prime}, z^{\prime}\right)^{\prime}$, let's consider the following unconstrained VAR model:

$$
W_{t}=\sum_{i=1}^{p} \Phi_{i} W_{t-i}+\varepsilon_{t},
$$

where $\Phi_{i}$ represent the coefficient matrices and $\varepsilon_{t}$ are independent and identically distributed with $\mathrm{E}\left(\varepsilon_{t}\right)=0, \mathrm{E}\left(\varepsilon_{t} \varepsilon_{t}^{\prime}\right)=\Sigma_{\varepsilon}$, a nonsingular covariance matrix of residuals and $\mathrm{E}\left(\varepsilon_{t} \varepsilon_{s}^{\prime}\right)=0$, for all $t \neq s$. To compute causality measures, we also need constrained models, meaning:

- A model where only $x$ and $z$ are included. The corresponding residual covariance matrix is noted $\Sigma_{0}$. This constrained model will serve to gauge causality from $y$ to $x$;

- A model with only $y$ and $z$. The corresponding residual covariance matrix is noted $\Sigma_{0}^{*}$. This constrained model aims at measuring causality from $x$ to $y$.

More precisely, causality measures are based on the comparison of the covariance matrix of the forecast error of $W_{t+h}$ obtained with the unconstrained and the constrained models. First, note that the forecast errors for horizon $h$ are given by:

$$
W_{t+h}-\mathrm{E}_{t}\left(W_{t+h}\right)=\sum_{i=0}^{h-1} A^{i} \varepsilon_{t+h-i}
$$

with $A$ the matrix of parameters stemming from the companion form of $W$, such as $\widetilde{W}=$ $A \widetilde{W}_{t-1}+\widetilde{\varepsilon}_{t}$, with $\widetilde{W}=\left(W_{t}, W_{t-1}, \ldots, W_{t-p+1}\right)^{\prime}$ and $\widetilde{\varepsilon}_{t}$ is a vector $\left(\varepsilon_{t}, 0, \ldots, 0\right)^{\prime}$. Repeatedly 
substituting for $\widetilde{W}$ leads to an equation where $\widetilde{W}_{t+h}$ depends on current and past innovations, such as:

$$
\widetilde{W}_{t+h}=\widetilde{\varepsilon}_{t+h}+A \widetilde{\varepsilon}_{t+h-1}+A^{2} \widetilde{\varepsilon}_{t+h-2}+\ldots+A^{h-1} \widetilde{\varepsilon}_{t+1}+A^{h} \widetilde{W}_{t}
$$

Second, it follows that the covariance matrix of these forecast errors for the unconstrained model is:

$$
\Sigma(h)=\sum_{i=0}^{h-1} A^{i} \Sigma_{\varepsilon} A^{i^{\prime}} .
$$

The same rational holds for the two constrained models.

Finally, as defined by Dufour and Taamouti (2010), causality from $y$ to $x$ for horizon $h$ is given by:

$$
C(y \stackrel{h}{\rightarrow} x \mid F)=\ln \left[\frac{\operatorname{det}\left[J_{0} \Sigma_{0}(h) J_{0}^{\prime}\right]}{\operatorname{det}\left[J_{1} \Sigma(h) J_{1}^{\prime}\right]}\right],
$$

where $F$ defines the information set. $\Sigma(h)$ is the residual covariance matrix of the unconstrained model for horizon $h$, whereas $\Sigma_{0}(h)$ is the covariance matrix from the constrained model without $y . J_{0}=\left[\begin{array}{ll}1 & 0\end{array}\right]$ and $J_{1}=\left[\begin{array}{lll}1 & 0 & 0\end{array}\right]$ serve to identify the block of the covariance matrices that corresponds to $x$. The determinant of the covariance matrix of the forecast errors from the constrained model - at the numerator - should be higher than (equal to) the determinant of the covariance matrix corresponding to the unconstrained model - at the denominator - if $y$ causes (does not cause) $x$. Thus, the higher the information content of $y$, the higher the numerator, and thus the higher the measure of causality $C(y \stackrel{h}{\rightarrow} x \mid F)$, for any horizon $h$. Otherwise, in the absence of causality from $y$ to $x$, for any horizon $h, C(y \stackrel{h}{\rightarrow} x \mid F)$ would be equal to zero.

The measure of causality from $x$ to $y$, for any horizon $h$, is defined in a similar way:

$$
C(x \stackrel{h}{\rightarrow} y \mid F)=\ln \left[\frac{\operatorname{det}\left[J_{0}^{*} \Sigma_{0}^{*}(h) J_{0}^{*^{\prime}}\right]}{\operatorname{det}\left[J_{1}^{*} \Sigma(h) J_{1}^{*^{\prime}}\right]}\right]
$$

with $\Sigma_{0}^{*}(h)$ the covariance matrix of the forecast errors at horizon $h$ obtained from the constrained model with only $y$ and $z$. Now $J_{0}^{*}=\left[\begin{array}{ll}1 & 0\end{array}\right]$ and $J_{1}^{*}=\left[\begin{array}{lll}0 & 1 & 0\end{array}\right]$ are used to select the blocks corresponding to the variable $y$ in the covariance matrices $\Sigma_{0}^{*}(h)$ and $\Sigma(h)$. The higher the information content of $x$, the higher the numerator, and thus the higher $C(x \stackrel{h}{\rightarrow} y \mid F)$.

For ease of reading, we will express each causality measure as a percentage of the total 
dependence between $x$ and $y$ for any horizon $h$. This total dependence is defined in Appendix A1. Furthermore, in order to gauge the statistical significance of our causality measures, we compute confidence intervals by implementing a bootstrap-after-bootstrap method that corrects for small-sample bias and skewness. The details concerning the 4-step procedure that we concretely follow to estimate the causality measures and to gauge their statistical significance is provided in Appendix A2.

\section{Data description}

We apply the methodology described in the previous section to Eurozone monthly data over the period 2000M1 - 2008M4 (100 observations). Data is retrieved from Datastream and from the ECB Statistical Data Warehouse. The time span is chosen so that a complete business cycle is covered in the analysis, from peak to peak. As Buch et al. (2014), we exclude the period after the outbreak of the subprime crisis, as unconventional monetary policy measures have been implemented by the ECB and our $x$ variable would not accurately capture this. Moreover we are interested in explaining the increase in systemic risk, up to the outbreak of the GFC, not in its consequences or its unwinding. We do however include in our sample the period of the Dot-Com crisis $(2000-2002)$. During these years, monetary policy was accommodating and the actions taken by the central bank to reduce the consequences of the crisis. This is an important source of moral hazard, which is one of the mechanisms underlying the SRTC.

As in Altunbas et al. (2014), Delis et al. (2017), Maddaloni and Peydro (2011) or Bruno et al. (2017), among others, our baseline measure of the monetary policy stance $(x)$ is based on the deviation of actual interest rates from a benchmark defined by a Taylor-type rule. This monetary policy "deviance" is called "Taylor residuals". When using such a measure, Hofmann and Bogdanova (2012) for instance find that actual policy rates were well below the levels implied by the Taylor rule over the period that we consider. Following these studies, our benchmark is a standard Taylor rule with gradual adjustment, which defines the Taylor rate as: $i_{t}^{*}=\beta_{i} i_{t-1}^{*}+\left(1-\beta_{i}\right)\left\{r r_{t}^{*}+\bar{\pi}+\beta_{\pi}\left(\pi_{t}-\bar{\pi}\right)+\beta_{y}\left(y_{t}-y_{t}^{*}\right)\right\} . \pi$ is the inflation rate. As it is usual in the empirical literature for countries that are not officially inflation targeters, the inflation target $\bar{\pi}$ is set equal to the mean value of the inflation rate over $2000-2008$. The 
corresponding value is 2.08 , which is very close to the upper bound of definition of price stability for the European Central Bank. ${ }^{9}$ The output gap $\left(y_{t}-y_{t}^{*}\right)$ is the difference between the level of industrial production and its HP filter trend. $r r_{t}^{*}$ is the time-varying equilibrium real interest rate. Following Hofmann and Bogdanova (2012), it corresponds to the trend growth rate (TGR) as estimated by the trend filter used to construct the output gap. As it is usual, the reaction parameters $\beta_{\pi}$ and $\beta_{y}$ are set equal to 1.5 and 0.5 , respectively, while $\beta_{i}$ is equal to 0.9 , as obtained on average in the literature. The monetary policy stance $(x)$ is computed as the difference between the actual nominal short term interest rate $i_{t}$ and the benchmark $i_{t}^{*}$. Figure 6 in Appendix B shows that the corresponding Taylor residuals were clearly negative from 2001 to 2007, which confirms the "too loose too long" suspicion. Note that, as a matter of robustness, we will consider alternative measures of monetary policy stance in the section devoted to the sensitivity analysis.

The variable representing systemic risk in our analysis $(y)$ is the aggregate SRisk (Acharya et al., 2012; Brownlees and Engle, 2016). At the individual level, SRisk corresponds to "the expected capital shortfall of a given financial institution, conditional on a crisis affecting the whole financial system" (Benoit et al., 2017). Therefore, the institutions with the highest SRisk are the greatest contributors to systemic risk. Engle et al. (2015) transposed the SRisk to the European case in order to determine systemically important financial institutions (SIFIs). To compute it, they use data on the market capitalization of firms, their financial leverage and data related to the sensitivity of the equity return to market shocks. Consequently, this measure accounts not only for the size of the institution and its individual risk, but also for the correlations between the market and the firm's return. It hence takes into account the two main components of systemic risk - size and interconnectedness.

This measure has been largely used in the literature on systemic risk as it presents numerous advantages. First, the SRisk has theoretical foundations. ${ }^{10}$ Second, it can be computed using publicly available data, which allows for timely results able to detect sudden shifts in systemic risk. Third, the measure proves to perform well not only at identifying and ranking SIFIs, but

\footnotetext{
${ }^{9}$ Unsurprisingly, all the results remain unchanged if we consider $\bar{\pi}=2.0$ instead of the mean value 2.08.

10 The SRisk is derived from the theoretical model of Acharya et al. (2017) who show that the negative externalities of a financial firm in a crisis are proportional to the capital shortage the firm experiences during the period of turmoil.
} 
also at predicting which institutions are going to be confronted with losses during a financial crisis. Using pre-crisis data Brownlees and Engle (2016) show that the SRisk successfully identifies banks that were more likely to be bailed out. Based on historical data, Brownlees et al. (2017) prove that the SRisk is able to identify SIFIs up to six months prior to the panic events considered. Fourth, as pointed out by Acharya et al. (2016), the way in which the SRisk is defined is conceptually similar to the methodology followed in the EU-wide stress tests.

It is common in the literature on systemic risk to also construct an aggregate measure of systemic risk, by summing the SRisk of individual institutions. The idea behind this aggregation is that the total amount of capital that would be needed to bail out the financial system if a financial crisis were to occur is the sum of all the capital needed by each institution. Therefore, for the purpose of our macroeconomic level analysis, we use the aggregate version of the measure to seize systemic risk in Europe. This aggregate SRisk is based on four types of financial firms: banking institutions, insurance companies, financial services and real estate firms. Brownlees and Engle (2016), Engle et al. (2015) and Brownlees et al. (2017) show that in its aggregate version, the SRISK also provides early warning signals of worsening macroeconomic conditions. ${ }^{11}$

In line with what we have learned after the outbreak of the crisis about insidious risk accumulation, this indicator started increasing in 2002, as it can be seen in Figure 6 (Appendix B). No other risk measure captured this risk accumulation before the crisis. ${ }^{12}$ Note that, in the robustness section, we will consider two alternative proxies for systemic risk.

As previously mentioned (see Section 2), it is important to include in our analysis auxiliary variables $z$ related to the perception of firms' and banks' riskiness. First, we consider two variables that are likely to capture "global risk perception": the VSTOXX index, based on Euro Stoxx 50 and designed to reflect market expectations of volatility, and a Global Risk Aversion Indicator (GRAI) provided by the ECB. Next, regarding firms, we retain five variables that are supposed to capture the perception of their riskiness (by banks and/or investors): 1) the risk premium, defined as the difference between the bank lending rate and the 3-month monetary

\footnotetext{
11 For more details on the computation of SRisk and the evolution of aggregate SRisk by country and in Europe, see the Stern-NYU's V-Lab website at http://vlab.stern.nyu.edu/welcome/risk/.

12 The dynamics of other commonly used risk measures are provided in Figure 8 in Appendix B.
} 
rate, 2) the BBB spread, defined as the difference between the BBB Euro Non Financial Index and the 10-year German government bond yield, 3) the cost of equity for firms, 4) the expected default frequency, and 5) the stock market return. According to the SRTC, the first four variables should decrease in the wave of a long-lasting monetary policy easing. Meanwhile the value of firms' equity should increase. Finally, as asserted in Section 2, an expansionary monetary policy may lead to a misperception of banks' riskiness, which can be captured by lower financing conditions, here proxied by a measure of the cost of equity (for banks), and to lower expected default frequency (for banks), considered as another auxiliary variable. Therefore, such a context is conducive to a gradual degradation of banks' balance sheet, here captured by the capital-to-asset ratio. Details on all these auxiliary variables can be found in Table 2 and Figure 8 in Appendix B.

Nonetheless, the build-up of systemic risk is not immediate. The misperception of firms' and banks' riskiness gradually exacerbates financial disequilibrium and triggers a progressive degradation of both firms' and banks' balance sheets. The auxiliary variables $z$ are the vehicles for this build-up of risk. This expected time lag justifies the use of long-run causality measures. We expect no short run Granger causality (at least for $h=1$ ) from monetary policy to systemic risk. Such a causality would rather be significant after some time, once risk misperception has actually led to higher risk-taking, a degradation of firms' and banks' balance sheets and a worsening in systemic risk.

\section{Results}

Our econometric analysis allows us to measure causality from monetary policy to systemic risk (Policy $\rightarrow$ Risk) as well as the reverse causality (Risk $\rightarrow$ Policy). While the former can be viewed as a confirmation or a rejection of the RTC theory applied to systemic risk, the latter helps us to see whether or not monetary policy reacted to increasing systemic risk before the financial crisis.

The analysis is performed with three variables in the VAR system and the lag is selected by AIC. We include a time trend in all models and compute the measures for a horizon $h$ from 
1 to 24 months. $^{13}$

Figure 1 presents causality measures (solid lines) from $x$ to $y$ (Policy $\rightarrow$ Risk, left panel) and from $y$ to $x$ (Risk $\rightarrow$ Policy, right panel). Dashed lines represent the $95 \%$ confidence intervals. Given that we present causality measures as percentages of the total dependence between $x$ and $y$, the values of our measures are necessarily comprised between 0 and 1 . Therefore, whenever the lower bound of the confidence interval is equal to 0 the measure is not significant (irrespective of the position of the upper bound). ${ }^{14}$ On the x-axis we have the time horizon in months, from 1 to 24 . The auxiliary variable is the volatility index, VSTOXX. As volatility was low in financial markets during the period of accommodating monetary policy, this index could have contributed to the misperception of risk and encouraged investors to take more risk. One interesting feature that can be seen in the first panel, is that, at horizon one, causality does not appear to be significant, underlining the importance of conducting this type of study in a long-run perspective. Indeed, using short-run causality tests, as usual Granger tests or Geweke measures, would have led to the sole conclusion of no causality. Nevertheless, starting with horizon two, the measure becomes significant. Moreover, the measure explains more than $70 \%$ of the total dependence between Policy and Risk, and the measure stays significant until horizon 24. This is consistent with the idea according to which the build up of systemic risk, as a consequence of a too loose monetary policy stance, is not immediate, but rather a progressive process.

Turning to causality from Risk to Policy, we can notice that the level of systemic risk in the economy does not seem to cause, at any horizon, the monetary policy stance. ${ }^{15}$ This is consistent with the fact that financial stability was not an objective per se for the ECB before the GFC, in line with the "cleaning up" paradigm that prevailed at that time. ${ }^{16}$

\footnotetext{
${ }^{13}$ In the robustness section, we also add different control variables when estimating the VAR model.

14 Note that, whenever the confidence interval bound is either 0 , or 1 , the corresponding dashed line is not visible on the graph. This holds for all figures that follow. The lower bound of the confidence interval is computed as the fractile at $2.5 \%$ of bias-corrected causality measures issued from the bootstrap-after-bootstrap procedure. Similarly, the upper bound of the confidence interval is the fractile at $97.5 \%$ of the bias-corrected causality measures issued from the bootstrap-after-bootstrap procedure. See Appendix A2, Step 4, for more details on this methodology.

15 While causality from $x$ to $y$ explains about $75 \%$ of the total dependence between $x$ and $y$, the remaining dependence is explained by instantaneous causality. See Appendix A1 for details.

16 Given the spread of the confidence intervals, we cannot precisely assess how much of the total dependence between $x$ and $y$ is explained by the percentage of long-run causality from $x$ to $y$.
} 
Figure 1: Causality measures for $\mathrm{z}=$ VSTOXX index
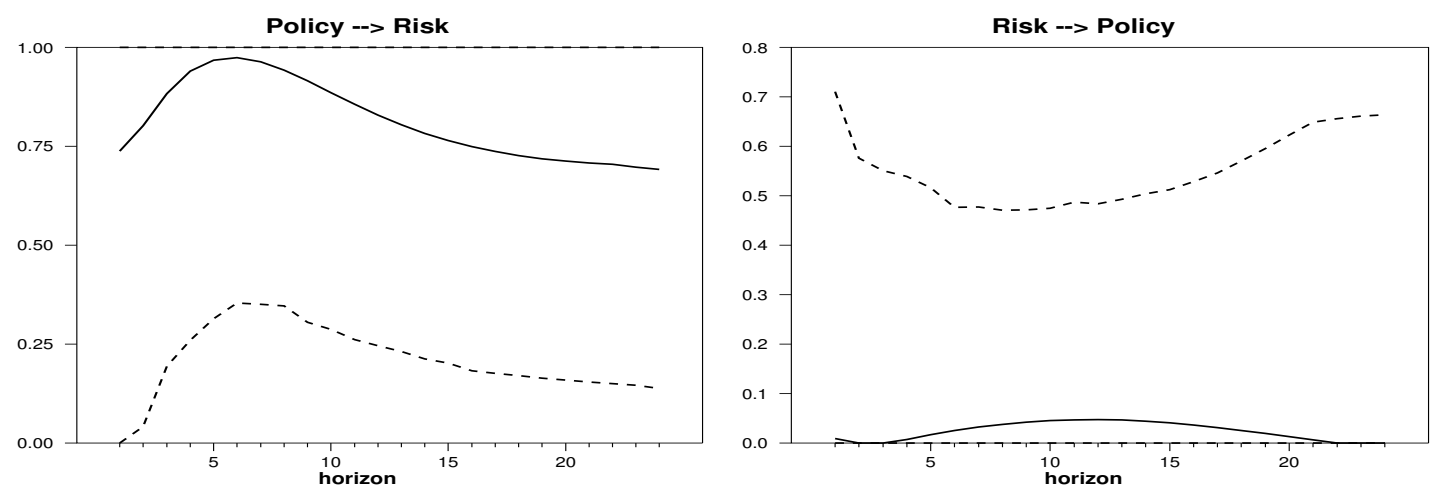

Note: This figure presents causality measures for the variables $x$ (Policy) and $y$ (Risk). More precisely, $\mathrm{x}=$ Taylor residuals and $\mathrm{y}$ $=$ SRisk. The auxiliary variable is the VSTOXX index. The order of the VAR, selected by AIC, is 2 . Confidence intervals at $95 \%$ are represented by the dashed lines.

When changing the auxiliary variable to GRAI, the Global Risk Aversion Indicator, results seem to further confirm the SRTC theory. In Figure 2, the monetary policy stance significantly influences systemic risk only starting with horizon 3. Once again, causality from Policy to Risk explains more than $75 \%$ of the total dependence between these two variables and causality from Risk to Policy is rejected.

Figure 2: Causality measures for $\mathrm{z}=$ Global Risk Aversion Indicator
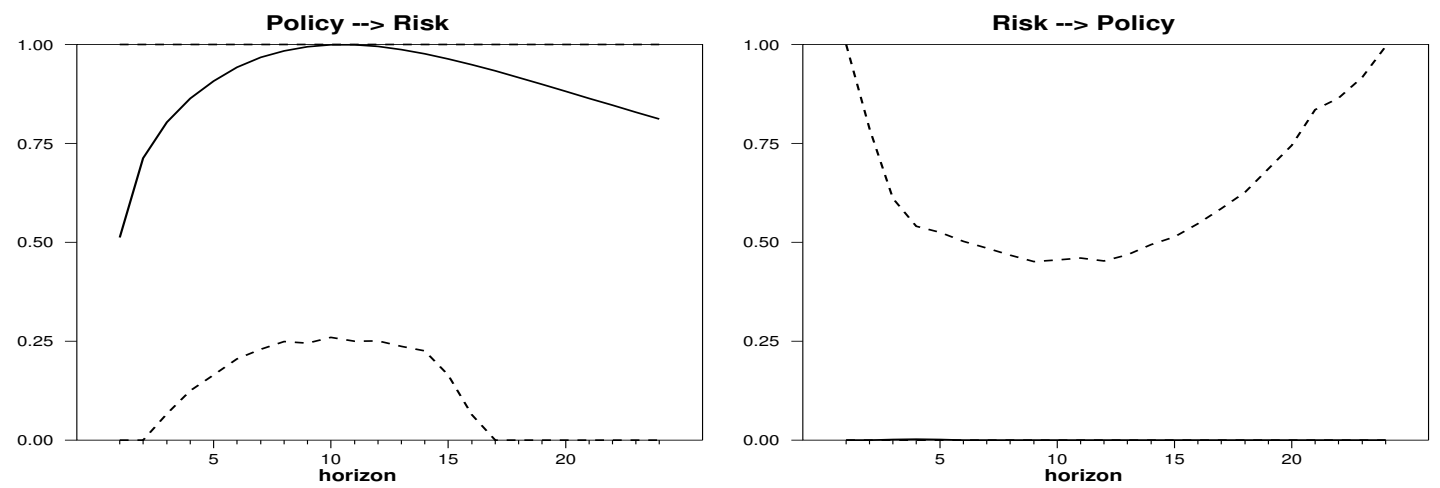

Note: This figure presents causality measures for the variables $x$ (Policy) and $y$ (Risk). More precisely, $\mathrm{x}=$ Taylor residuals and $\mathrm{y}$ $=$ SRisk. The auxiliary variable is the Global Risk Aversion Indicator. The order of the VAR, selected by AIC, is 1 . Confidence intervals at $95 \%$ are represented by the dashed lines.

The two variables considered above relate to the global risk perception. Results converge towards the existence of a SRTC in Europe and the need for policy to stay low for long in order for this transmission channel to start operating. We turn now to variables that are more directly related to the perception of firms' and banks' riskiness. 
Figure 3 presents causality measures when the auxiliary variable is the BBB Euro Non Financial Index spread with respect to the 10-year German government bond yields. This spread was at its low during the period of expansionary policy, implying that firms with a BBB investment grade were perceived, at that time, as less risky. In this scenario, the policy stance is an evident predictor of systemic risk. Starting with period 4, the causality measure Policy $\rightarrow$ Risk becomes significant and explains more than $75 \%$ of total causality, proving, as in the above cases, that monetary policy needs to be accommodating for a longer time period in order for the SRTC to become active. Moreover, from horizon 9 on, the spread of the confidence interval diminishes, implying an increased significance of the measure. ${ }^{17}$

Figure 3: Causality measures for $\mathrm{z}=\mathrm{BBB}$ rated firms bond index spread
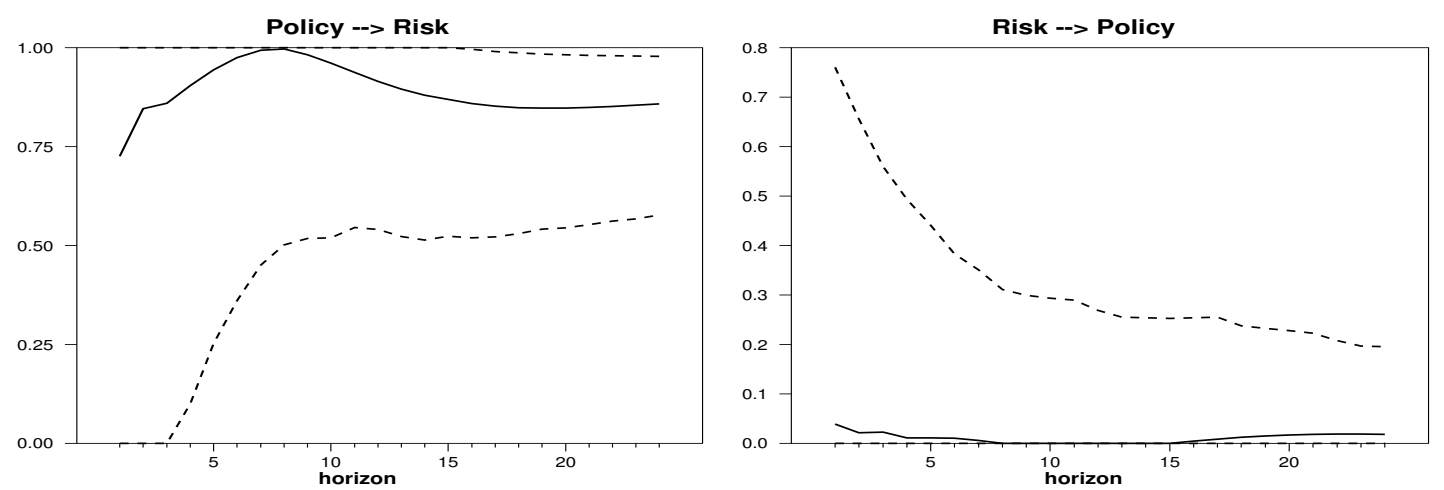

Note: This figure presents causality measures for the variables $x$ (Policy) and $y$ (Risk). More precisely, $\mathrm{x}=$ Taylor residuals and $\mathrm{y}$ $=$ SRisk. The auxiliary variable is the spread between the BBB rated firms bond index and the 10-year German government bond yields. The order of the VAR, selected by AIC, is 3. Confidence intervals at $95 \%$ are represented by the dashed lines.

In Figure 4, we present causality measures for the case where the auxiliary variable is the expected default frequency of non financial corporations, another variable related to the perception of firms and banks' riskiness. According to the mechanisms underlying the SRTC, when this probability decreases, financial institutions should lower their lending standards and be agree to finance riskier projects. Results in Figure 4 seem to confirm this hypothesis, as the causality measure from Policy to Risk is significant and increasing starting with period 3. Again, causality from Policy to Risk explains more than $75 \%$ of the total dependence.

Considering as auxiliary variable the banks' capital-to-asset ratio further confirms our results. This ratio was rather stable during the period 2003 to 2007, implying no particular

\footnotetext{
17 The narrower confidence interval that we obtain with the BBB spread may indicate that this variable better captures the (mis)perception of firms' riskiness than the other auxiliary variables.
} 
Figure 4: Causality measures for $\mathrm{z}=$ Expected default frequency (firms)
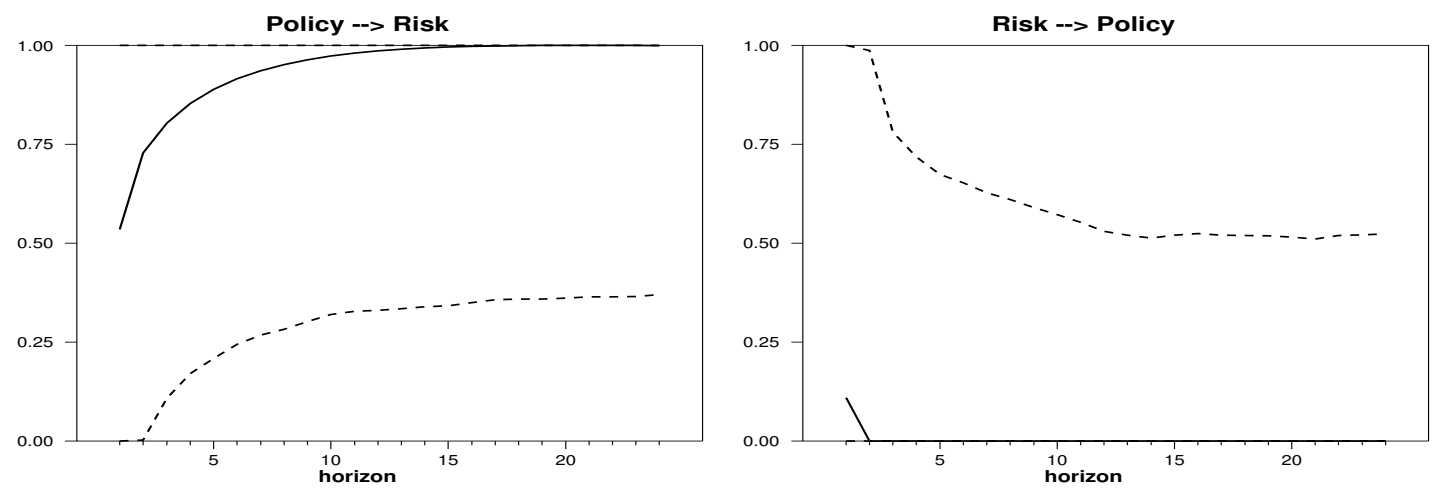

Note: This figure presents causality measures for the variables $x$ (Policy) and $y$ (Risk). More precisely, $\mathrm{x}=$ Taylor residuals and $\mathrm{y}$ $=$ SRisk. The auxiliary variable is the Expected default frequency (firms). The order of the VAR, selected by AIC, is 1 . Confidence intervals at $95 \%$ are represented by the dashed lines.

problems for the banking sector. Figure 5 shows that the impact of the policy stance on systemic risk is present in this configuration, starting with period 1. These last three figures validate our intuition about the connections between the systemic risk-taking channel and firms' and banks' balance sheets structure. The graphs for all the other auxiliary variables are provided in Appendix C (Figures 9 to 13). For one single auxiliary variable - expected default frequency of banks - no causality is found, neither from Risk to Policy, nor from Policy to Risk. The result would imply that the expected probability of default for the banking sector did not play a role in systemic risk accumulation or is not a good proxy for the perception of banks' riskiness. ${ }^{18}$

Figure 5: Causality measures for $\mathrm{z}=$ Capital-to-asset ratio
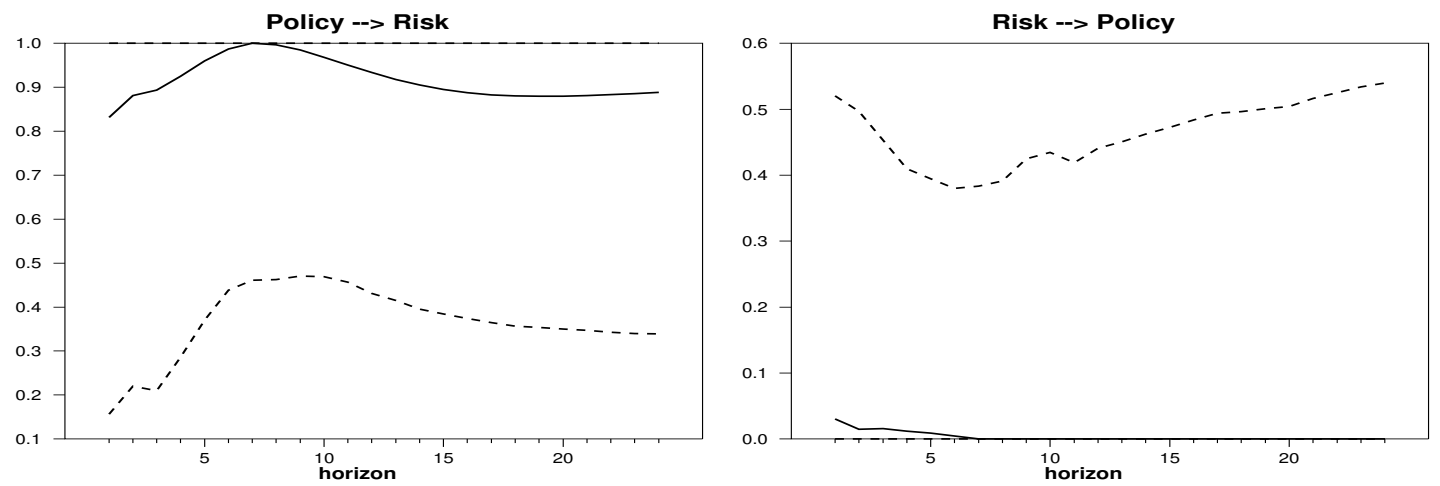

Note: This figure presents causality measures for the variables $x$ (Policy) and $y$ (Risk). More precisely, $\mathrm{x}=$ Taylor residuals and $\mathrm{y}$ $=$ SRisk. The auxiliary variable is the Capital-to-asset ratio. The order of the VAR, selected by AIC, is 3 . Confidence intervals at $95 \%$ are represented by the dashed lines.

Otherwise, evidence of causal relationships from monetary policy to risk is found with

\footnotetext{
18 Nevertheless, long-run causality from $x$ to $y$ is found to be significant with this auxiliary variable in some alternative specifications tested below in the robustness section.
} 
all the other auxiliary variables, namely: the risk premium, the stock market index and the cost of equity for firms and for banks. Furthermore, our results seem to confirm the fact that central banks were not concerned with financial risk in the period preceding the crisis. More importantly, we reject, in several of the configurations considered, the presence of shortrun causality from monetary policy to risk. This justifies the adequacy of our methodology, although it has never been employed before in this literature. All in all, the results conclude to the existence, at a macroeconomic level, of a SRTC in the Eurozone. To confirm these results, the above analysis was conducted using several auxiliary variables, $z$. In the next section, more robustness tests are provided.

\section{$6 \quad$ Sensitivity analysis}

To verify the robustness of our results, we perform three different exercises. For the first one, we change the way in which we measure the monetary policy stance, $x$. To start with, we consider Taylor rules which are more or less different from the baseline. More precisely, we define Taylor residuals (2) as the difference between the actual nominal interest rate and a benchmark that is close to the baseline, but without gradualism $\left(\beta_{i}=0\right)$, as in Hofmann and Bogdanova (2012). Taylor (3) is an alternative benchmark without gradualism, but with forward-looking features and a constant equilibrium real interest rate, that is: $i_{t}^{*}=0.63+1.5 \pi_{t+12}+0.5\left(y_{t}-y_{t}^{*}\right)$. The value for the constant stems from preliminary estimations. ${ }^{19}$ Taylor (4) is equivalent to the baseline rule, but with a forward-looking behavior for inflation. Finally, Taylor (5) is an alternative benchmark based on Orphanides and Wieland (2013). According to this rule the change in the policy rate responds to forward-looking inflation and the difference in output gap: $\Delta i_{t}^{*}=0.5\left(\pi_{t+12}-\bar{\pi}\right)+0.5 \Delta\left(y_{t}-y_{t}^{*}\right)$. Interest rates in level are then easily obtained following $i_{t}^{*}=i_{t-1}^{*}+\Delta i_{t}^{*}$. In each and every case, the Taylor residuals that we obtain are negative and confirm that interest rates were set too low too long before the GFC.

Next, departing from monetary policy rules, we also use, as an alternative measure of the

\footnotetext{
19 Knowing that the structural form of the rule is $r r_{t} *+\bar{\pi}+1.5\left(\pi_{t}-\bar{\pi}\right)+0.5\left(y_{t}-y_{t}^{*}\right)$, the estimated constant in Taylor (3) can be identified as $r r *+\bar{\pi}-1.5 \bar{\pi}$. Given that $\bar{\pi}=2.08$, a constant equal to 0.63 implies that the equilibrium real interest rate is equal to $r r *=1.67 \%$. This corresponds precisely to the mean value of the TGR over the considered period.
} 
monetary policy stance, $x$, the short-term nominal interest rate gap with respect to its HodrickPrescott HP trend (labeled interest gap). Last, monetary policy deviance is gauged through the difference between the real interest rate and its equilibrium (labeled real rate gap). Following Taylor (1993), among others, the time-varying equilibrium real interest rate is supposed to be equal to the estimate of the TGR of real activity $\left(r r_{t} *=\Delta y_{t}^{*}\right)$. These two additional measures are also represented in Figure 6 (Appendix B) and they both indicate a loose stance of monetary policy in the period leading up to the GFC.

Table 1 summarizes the main features of all the benchmarks we use to gauge the real monetary policy stance.

Table 1: Alternative measures of monetary policy stance

\begin{tabular}{lll}
\hline \hline \multicolumn{1}{c}{ Benchmark } & \multicolumn{1}{c}{ Definition of the benchmark } & Corresponding policy stance \\
\hline Taylor (baseline) & $i_{t}^{*}=0.9 i_{t-1}^{*}+0.1\left\{r r_{t}^{*}+\bar{\pi}+1.5\left(\pi_{t}-\bar{\pi}\right)+0.5 \tilde{y}_{t}\right\}$ & Taylor residuals \\
Taylor (2) & $i_{t}^{*}=r r_{t}^{*}+\bar{\pi}+1.5\left(\pi_{t}-\bar{\pi}\right)+0.5 \tilde{y}_{t}$ & Taylor residuals (2) \\
Taylor (3) & $i_{t}^{*}=0.63+1.5 \pi_{t+12}+0.5 \tilde{y}_{t}$ & Taylor residuals (3) \\
Taylor (4) & $i_{t}^{*}=0.9 i_{t-1}^{*}+0.1\left\{r r_{t}^{*}+\bar{\pi}+1.5\left(\pi_{t+12}-\bar{\pi}\right)+0.5 \tilde{y}_{t}\right\}$ & Taylor residuals (4) \\
Taylor (5) & $i_{t}^{*}=i_{t-1}+\Delta i_{t}^{*}$, with $\Delta i_{t}^{*}=0.5\left(\pi_{t+12}-\bar{\pi}\right)+0.5 \Delta \tilde{y}_{t}$ & Taylor residuals (5) \\
Interest trend & $i_{t}^{*}=H P\left(i_{t}\right)$ & Interest gap \\
Equilibrium real rate & $r r_{t}^{*}=\Delta y_{t}^{*}$, with $y_{t}^{*}=H P\left(y_{t}\right)$ & Real rate gap \\
\hline \hline
\end{tabular}

Note: $\tilde{y}_{t} \equiv\left(y_{t}-y_{t}^{*}\right)$, with $y_{t}^{*}=H P\left(y_{t}\right) . H P(x)$ means Hodrick-Prescott Filter applied to a variable $x$. All measures of the monetary policy stance are computed as the difference between the actual interest rate $i_{t}$ and the corresponding benchmark $i_{t}^{*}$, except for the real rate gap which is defined as the difference between the actual ex post real interest $r_{t}$ and the estimated equilibrium real rate $r r_{t}^{*} \cdot \bar{\pi}=2.08$, the mean inflation over the sample period.

All in all, we consider six alternative monetary policy specifications. When the auxiliary variables are related to the global risk perception (i.e. VSTOXX and GRAI), results are qualitatively similar to the ones obtained in the main analysis. The sole exception concerns Taylor residuals (4), where no causality is found either from monetary policy to systemic risk and vice versa. In all other five alternative specifications of $x$, long-run causality from $x$ to $y$ is significant, while reverse causality is generally rejected. Furthermore, when auxiliary variables concern the perception of firms' riskiness (BBB spread, risk premium, stock market index, expected default frequency and cost of equity), results from the main analysis seem to be confirmed in most configurations. The BBB spread and the cost of equity for firms appear as being the auxiliary variables through which the SRTC works most. For the stock 
market return, and to a lesser extent, the risk premium and firms' expected default frequencies, results indicating the presence of long-run causality from $x$ to $y$ are more mixed. Causality from systemic risk to the monetary policy stance is once again globally rejected. Finally, all three auxiliary variables related to the perception of banks' riskiness - banks' expected default frequencies, the cost of equity and the capital-to-asset ratio - in all six monetary policy configurations, give similar results to the ones presented in the baseline analysis: long-run causality from $x$ to $y$ is always significant, while short-run causality is almost never present. As before, causality from $y$ to $x$ is generally rejected. From the six alternative monetary policy stance measures, four seem to strongly confirm the existence of a SRTC in Europe: Taylor residuals (2) and (5), the interest gap and real rate gap. When Taylor residuals (4) is used as a proxy for the monetary policy stance, ${ }^{20}$ global risk perception and firms' perceived riskiness (via the risk premium, the stock market index and the expected default frequency) do not seem to play a major role in the transmission of monetary policy to systemic risk. Moreover, Taylor residuals (3) highlight a new configuration, where some causality from $y$ to $x$ is found at small horizons (from 1 to maximum 4), implying thus some reaction of the central bank to the increase in systemic risk. Nevertheless, this evidence is not robust, as it does not appear in any other configuration. Generally, the results are always robust when causality from $x$ to $y$ is gauged through auxiliary variables related to the perception for banks' riskiness. These results are all summarized in Tables 3 to 6 in Appendix D.

The second robustness exercise consists in including control variables in the VAR model and re-evaluating the benchmark results to see whether causality still holds in this new setting. To this end, we have considered three categories of control variables, all provided by the ECB (Statistical Data Warehouse). First, we control for the economic activity. However, as the output gap is already taken into account in the policy measure (Taylor residuals), it would be redundant to include it in the VAR. Instead, we consider the unemployment rate. Second, we check whether inserting variables related to external factors, namely the US Fed Funds rate and the real effective exchange rate (EUR/USD), would affect our causality results. Last, given that the SRTC relies on private agents' perceptions, it is important to consider their perception

\footnotetext{
20 Taylor residuals (4) only differs from the benchmark treated in the main analysis in that inflation has a forward-looking behavior.
} 
of future economic activity, through the expected growth rate. Including unemployment into the VAR confirms our benchmark results. Only two auxiliary variables, GRAI and firms' risk premium, do not allow us to conclude to a significant causality from Policy to Risk. Results are again similar to the ones in the main analysis when external factors are taken into account. The only variable that does not lead to a significant causality measure from Policy to Risk is GRAI. No changes with respect to the results section are observed when the expected growth rate is added as an exogenous variable. All in all, our results seem robust to including different control variables, confirming once more the existence of the SRTC in Europe. Results from this analysis are summarized in Tables 7 to 10 in Appendix D.

The last type of sensitivity analysis concerns the systemic risk variable $y$. Two alternative risk measures are considered. ${ }^{21}$ The first one, labeled SRisk_bk, is a measure of SRisk related to the sole banking sector. It is computed in a similar way to the original SRisk, but excludes insurance companies, financial services and real estate firms. As reported in the Appendix D, Table 11, the results with SRisk_bk still lead, in most of the cases, to the confirmation of the SRTC in Europe. The only two variables for which there is no causality from Policy to Risk are stock prices and banks' the expected default frequency. We also test the robustness of our results by using the credit-to-GDP gap with respect to its HP trend. Although this variable is not per se a measure of systemic risk, it is often viewed as a good indicator of global risk, notably by the Basel Committee. Once more, the results for most of the $z$ variables indicate the existence of long-run causality from Policy to Risk, but not from Risk to Policy.

The results obtained in the baseline analysis and in all the robustness checks are clearly in favor of the existence of the SRTC in the Eurozone. Since these results are conclusive when using only one auxiliary variable in the model, we argue that accounting for more auxiliary variables at a time would be redundant. This is even more the case as these variables are closely connected and therefore their impact would be difficult to disentangle in a VAR model with four or more variables, therefore adding nothing new to the analysis.

\footnotetext{
21 The dynamics of these two risk measures are plotted in Figure 7 in Appendix B. They clearly show evidence of risk accumulation during the period of the study. Typically, the credit-to-GDP gap is positive starting with the end of 2004, implying an increase in credit and potentially more risk.
} 


\section{Concluding Remarks}

The RTC has gained a lot of attention since the outbreak of the financial crisis, as it represents a way of explaining why the crisis was so severe and why risk accumulation went unnoticed. However, while liquidity or default risk have been considered in this literature, systemic risk has been largely neglected. Furthermore, the different studies conducted thus far mainly perform micro-econometric analyses. Macroeconomic studies are scarce and the long-term perspective is not considered, while the build up of systemic risk, as a consequence of too loose monetary policy stance, is not likely to be immediate. Finally, none of the existing papers employs causality measures which, as we have shown, are suitable for treating the existence of the RTC. As an extension to this literature, we propose an original methodology to investigate the link between monetary policy and systemic risk.

Several aspects of the SRTC are addressed in this paper. First, given that expansionary monetary policy needs an "incubation period" before influencing systemic risk behavior, we adopt a long-run perspective and compute causality measures over different horizons. We find that in most cases, causality from the monetary policy stance to systemic risk becomes significant after several months. Therefore, usual short-run causality measures à la Granger and à la Geweke would not have been adequate for the research question at hand. According to our estimates, the causality from monetary policy to systemic risk, while not significant in the very short term, robustly represents 75 to $100 \%$ of the total dependence between the two variables in the long run.

Second, causality from systemic risk to the monetary policy stance is also estimated. Interestingly, our results show no such causal relation in this direction. This finding is not so surprising as financial stability was not an objective per se of the ECB before 2008. However, as part of the two pillar strategy adopted by the ECB, financial indicators were supposed to be monitored as they may contain information about future inflation. If evidence provided here proves that this was not the case, the explanation may come not from a lack of vigilance of the central bank, but most probably from an absence of reliable risk measures. We address this second issue by employing a recently proposed systemic risk measure, namely the SRisk indicator, that reproduces the slow and long risk accumulation that preceded the crisis. 
Central banks must be aware that a too loose monetary policy stance may be conducive to negative externalities such as the progressive build-up up of systemic risk. Should therefore central banks react to systemic risk? In other words, would it have been desirable in our empirical investigation to validate reverse causality, from systemic risk to monetary policy? This is an ongoing debate. According to Smets (2014), there are two main opposite views. On the one hand, the "leaning against the wind" approach considers that central banks should not hesitate to use monetary policy to address financial imbalances. On the other hand, the "modified Jackson Hole consensus" calls central banks to only focus on price stability, while the objective of financial stability should be entrusted to another institution, with its own objectives and instruments. However systemic risk per se has not really been addressed in this debate. Therefore, this issue deserves more developments, possibly in the way suggested by Brunnermeier and Sannikov (2014).

In the meanwhile, the resilience of the economy could be enhanced by macro-prudential policy. By preventing systemic risk, macro-prudential policy may offset the negative externalities of "too long too low" interest rates. This should become a matter of priority, as monetary policy has been very accommodating in many countries for nearly ten years now. 


\section{References}

[1] Acharya, V. and M. Richardson (2009). Restoring financial stability: how to repair a failed system. Vol. 542. John Wiley and Sons.

[2] Acharya, V., R. Engle, and M. Richardson (2012). "Capital shortfall: A new approach to ranking and regulating systemic risks". American Economic Review 102.3, pp. 59-64.

[3] Acharya, V. V., D. Pierret, and S. Steffen (2016). Introducing the "Leverage Ratio" in Assessing the Capital Adequacy of European Banks. Tech. rep. Mimeo ZEW.

[4] Acharya, V. V., L. H. Pedersen, T. Philippon, and M. Richardson (2017). "Measuring systemic risk". The Review of Financial Studies 30.1, pp. 2-47.

[5] Adrian, T. and H. Shin (2009). "Money, Liquidity, and Monetary Policy". American Economic Review 99.2, pp. 600-605.

[6] Afanasyeva, E. and J. Güntner (2016). "Bank market power and the risk channel of monetary policy". mimeo.

[7] Allen, F. and E. Carletti (2009). "The global financial crisis: causes and consequences". Paper is presented on the Conference on: Global Market Integration and Financial Crises, The Hong Kong University of Science and Technology (HKUST) Business School.

[8] Altunbas, Y., L. Gambacorta, and D. Marqués-Ibáñez (2014). "Does Monetary Policy Affect Bank Risk?" International Journal of Central Banking 10.1, pp. 95-135.

[9] Angeloni, I., E. Faia, and M. Lo Duca (2015). "Monetary Policy and Risk Taking". Journal of Economic Dynamics and Control 52.C, pp. 285-307.

[10] Bekaert, G., M. Hoerova, and M. L. Duca (2013). "Risk, Uncertainty and Monetary Policy". Journal of Monetary Economics 60.7, pp. 771-788.

[11] Benoit, S., J.-E. Colliard, C. Hurlin, and C. Pérignon (2017). "Where the risks lie: A survey on systemic risk". Review of Finance 21.1, pp. 109-152. 
[12] Bernanke, B. (2013). "Testimony of Chairman Ben S. Bernanke before the Joint Economic Committee, U.S. Congress, Washington, D.C., May 22, 2013".

[13] Bernanke, B., M. Gertler, and S. Gilchrist (1999). "The Financial Accelerator in a Quantitative Business Cycle Framework". Ed. by J. Taylor and M. Woodford. Amsterdam : North-Holland. Vol. 1. Handbook of Macroeconomics. Chap. 21, pp. 1341-1393.

[14] Bonfim, D. and C. Soares (2014). "The risk-taking channel of monetary policy - exploring all avenues". Banco de Portugal Working paper 2.

[15] Borio, C. and H. Zhu (2012). "Capital regulation, risk-taking and monetary policy: A missing link in the transmission mechanism?" Journal of Financial Stability 8.4, pp. 236251.

[16] Brownlees, C. and R. F. Engle (2016). "SRISK: A Conditional Capital Shortfall Measure of Systemic Risk". The Review of Financial Studies 30.(1), pp. 48-79.

[17] Brownlees, C. T., B. R. Chabot, E. Ghysels, and C. J. Kurz (2017). Back to the Future: Backtesting Systemic Risk Measures During Historical Bank Runs and the Great Depression. Tech. rep.

[18] Brunnermeier, M. and Y. Sannikov (2014). "A Macroeconomic Model with a Financial Sector". American Economic Review 104.2, pp. 379-421.

[19] Brunnermeier, M. (2001). Asset Pricing under Asymmetric Information - Bubbles, Crashes, Technical Analysis and Herding. Oxford, Oxford University Press.

[20] Bruno, V., I. Shim, and H. S. Shin (2017). "Comparative assessment of macroprudential policies". Journal of Financial Stability 28.C, pp. 183-202.

[21] Buch, C., S. Eickmeier, and E. Prieto (2014). "In search for yield? Survey-based evidence on bank risk taking". Journal of Economic Dynamics and Control 43.C, pp. 12-30.

[22] Cao, J. and G. Illing (2015). "“Interest Rate Trap", or does the central bank keep the policy rate too low for too long?" The Scandinavian Journal of Economics 117.4, pp. 12561280. 
[23] Challe, E., B. Mojon, and X. Ragot (2013). "Equilibrium risk shifting and interest rate in an opaque financial system". European Economic Review 63.C, pp. 117-133.

[24] Chodorow-Reich, G. (2014). "Effects of unconventional monetary policy on financial institutions". Brookings Papers on Economic Activity 45.1, pp. 155-227.

[25] Cociuba, S. E., M. Shukayev, and A. Ueberfeldt (2016). "Collateralized borrowing and risk taking at low interest rates". European Economic Review 85, pp. 62-83.

[26] Davidson, R and J MacKinnon (2004). Econometric Theory and Methods. New York: Oxford University Press.

[27] De Nicolo, G., G. Dell'Ariccia, L. Laeven, and F. Valencia (2010). "Monetary policy and bank risk taking". IMF staff position note 10/09.

[28] Delis, M. and G. Kouretas (2011). "Interest rates and bank risk-taking". Journal of Banking and Finance 35.4, pp. 840-855.

[29] Delis, M. D., I. Hasan, and N. Mylonidis (2017). "The Risk-Taking Channel of Monetary Policy in the US: Evidence from Corporate Loan Data". Journal of Money, Credit and Banking 49.1, pp. 187-213.

[30] Dell'Ariccia, G. and R. Marquez (2006). "Lending Booms and Lending Standards". The Journal of Finance 61.5, pp. 2511-2546.

[31] Dell'Ariccia, G., L. Laeven, and R. Marquez (2014). "Real interest rates, leverage, and bank risk-taking". Journal of Economic Theory 149, pp. 65-99.

[32] Dell'Ariccia, G., L. Laeven, and G. Suarez (2017). "Bank Leverage and Monetary Policy's Risk-Taking Channel: Evidence from the United States". The Journal of Finance LXXII.2, pp. 613-654.

[33] Dewachter, H. and R. Wouters (2014). "Endogenous risk in a DSGE model with capitalconstrained financial intermediaries". Journal of Economic Dynamics and Control 43.C, pp. 241-268. 
[34] Diamond, D. and R. Rajan (2006). "Money in a Theory of Banking". American Economic Review 96.1, pp. 30-53.

[35] — (2009). "The Credit Crisis: Conjectures about Causes and Remedies". American Economic Review 99.2, pp. 606-10.

[36] - (2012). "Illiquid Banks, Financial Stability, and Interest Rate Policy". Journal of Political Economy 120.3, pp. 552-591.

[37] Drees, B., B. Eckwert, and F. Várdy (2013). "Cheap money and risk taking: Opacity versus fundamental risk". European Economic Review 62, pp. 114-129.

[38] Dubecq, S., B. Mojon, and X. Ragot (2015). "Fuzzy Capital Requirements, Risk-Shifting and the Risk Taking Channel of Monetary Policy". International Journal of Central Banking 11.1, pp. $72-101$.

[39] Dufour, J.-M. and E. Renault (1998). "Short Run and Long Run Causality in Time Series: Theory". Econometrica 66.5, pp. 1099-1125.

[40] Dufour, J.-M. and A. Taamouti (2010). "Short and long run causality measures: Theory and inference". Journal of Econometrics 154.1, pp. 42-58.

[41] Dufour, J.-M. and D. Tessier (1993). "On the relationship between impulse response analysis, innovation accounting and Granger causality". Economics Letters 42.4, pp. 327333.

[42] Engle, R., E. Jondeau, and M. Rockinger (2015). "Systemic Risk in Europe". Review of Finance 19.1, pp. 145-190.

[43] Farhi, E. and J. Tirole (2012). "Collective Moral Hazard, Maturity Mismatch and Systemic Bailouts". American Economic Review 102.1, pp. 60-93.

[44] Fisher, I. (1933). "The Debt Deflation Theory of Great Depressions". Econometrica 1, pp. $337-57$. 
[45] Gambacorta, L. (2009). "Monetary policy and the risk-taking channel". BIS Quarterly Review.

[46] Gambacorta, L. and D. Marques-Ibañez (2011). "The bank lending channel: Lessons from the crisis". Economic Policy 26.66, pp. 135-182.

[47] Gennaioli, N., A. Shleifer, and R. Vishny (2015). "Neglected Risks: The Psychology of Financial Crises". American Economic Review 105.5, pp. 310-314.

[48] Gertler, M. and P. Karadi (2011). "A model of unconventional monetary policy". Journal of Monetary Economics 58.1, pp. 17-34.

[49] Gertler, M., N. Kiyotaki, and A. Queralto (2012). "Financial crises, bank risk exposure and government financial policy". Journal of Monetary Economics 59, S17-S34.

[50] Geweke, J. (1982). "Measurement of Linear Dependence and Feedback between Multiple Time Series". Journal of the American Statistical Association 77.378, pp. 304-313.

[51] Gonzàles-Aguado, C. and J. Suarez (2015). "Interest rates and credit risk". Journal of Money, Credit and Banking 47.2-3, pp. 445-480.

[52] Hau, H. and S. Lai (2016). "Asset allocation and monetary policy: Evidence from the eurozone". Journal of Financial Economics 120.2, pp. 309-329.

[53] Hayek, F. A. von (1939). Profits, Interest and Investment. Routledge, London.

[54] He, Z. and A. Krishnamurthy (2014). "A Macroeconomic Framework for Quantifying Systemic Risk". NBER Working Paper 19885.

[55] Hofmann, B. and B. Bogdanova (2012). "Taylor Rules and Monetary Policy: A Global 'Great Deviation'?" BIS Quarterly Review.

[56] Holmstrom, B. and J. Tirole (1997). "Financial intermediation, loanable funds, and the real sector". The Quarterly Journal of Economics 112.3, pp. 663-691. 
[57] Ioannidou, V., S. Ongena, and J. Peydro (2015). "Monetary Policy, Risk-Taking, and Pricing: Evidence from a Quasi-Natural Experiment". Review of Finance 19.1, pp. 95144.

[58] Ivanov, V. and L. Kilian (2005). "A Practitioner's Guide to Lag Order Selection For VAR Impulse Response Analysis". Studies in Nonlinear Dynamics and Econometrics 9.1, pp. 1-36.

[59] Jiménez, G., S. Ongena, J. L. Peydró, and J. Saurina (2014). "Hazardous times for monetary policy: What do twenty-three million bank loans say about the effects of monetary policy on credit risk-taking?" Econometrica 82.2, pp. 463-505.

[60] Kilian, L. (1998). "Small-sample Confidence Intervals for Impulse Response Functions". Review of Economics and Statistics 80.2, pp. 218-230.

[61] — (2001). "Impulse Response Analysis in Vector Autoregressions with Unknown Lag Order". Journal of Forecasting 20.3, pp. 161-79.

[62] Kindleberger, C. P. (1978). Manias, Panics and Crashes: A History of Financial Crises. Basic Books, New York.

[63] Levieuge, G. (2009). "Bank Capital Channel and Counter-Cyclical Prudential Regulation in a DSGE Model". Louvain Economic Review 75.4, pp. 425-460.

[64] Lewis, R. and G. C. Reinsel (1985). "Prediction of multivariate time series by autoregressive model fitting". Journal of Multivariate Analysis 16.3, pp. 393-411.

[65] Maddaloni, A. and J. Peydro (2011). "Bank Risk-taking, Securitization, Supervision, and Low Interest Rates: Evidence from the Euro-area and the U.S. Lending Standards". Review of Financial Studies 24.6, pp. 2121-2165.

[66] Molina, C. (2005). "Are Firms Underleveraged? An Examination of the Effect of Leverage on Default Probabilities". Journal of Finance 60.3, pp. 1427-1459.

[67] Orphanides, A. and V. Wieland (2013). "Complexity and Monetary Policy". International Journal of Central Banking 9.1, pp. 167-204. 
[68] Paligorova, T. and J. Santos (2017). "Monetary policy and bank risk-taking: Evidence from the corporate loan market". Journal of Financial Intermediation 30.C, pp. 35-49.

[69] Rajan, R. (2006). "Has Finance Made the World Riskier?" European Financial Management 12.4, pp. 499-533.

[70] Sims, C. A., J. H. Stock, and M. W. Watson (1990). "Inference in Linear Time Series Models with some Unit Roots". Econometrica 58.1, pp. 113-144.

[71] Smets, F. (2014). "Financial Stability and Monetary Policy: How Closely Interlinked?" International Journal of Central Banking 10.2, pp. 263-300.

[72] Taylor, J. B. (1993). "Discretion versus policy rules in practice". Carnegie-Rochester Conference Series on Public Policy 39, pp. 195-214.

[73] Thakor, A. (2015). "Lending Booms, Smart Bankers, and Financial Crises". American Economic Review 105.5, pp. 305-309.

[74] Valencia, F. (2014). "Monetary policy, bank leverage, and financial stability". Journal of Economic Dynamics and Control 47, pp. 20-38. 


\section{Appendix}

\section{A. Details on causality measures and their statistical significance}

\section{A1: Formula for the measure of total dependence}

The measure of total dependence between $x$ and $y$ at horizon $h$ follows this formula:

$$
C(x-y \mid F)=\ln \left[\frac{\operatorname{det}\left[J_{0} \Sigma_{0}(h) J_{0}^{\prime}\right] \quad \operatorname{det}\left[J_{0}^{*} \Sigma_{0}^{*}(h) J_{0}^{*^{\prime}}\right]}{\operatorname{det}[G \Sigma(h) G]}\right]
$$

where $F$ defines the information set. $\Sigma(h)$ is the residual covariance matrix of the unconstrained model for horizon $h, \Sigma_{0}(h)$ is the covariance matrix from the constrained model without $y$ and $\Sigma_{0}^{*}(h)$ represents the covariance matrix of the forecast errors at horizon $h$ obtained from the constrained model with only $y$ and $z . J_{0}=\left[\begin{array}{ll}1 & 0\end{array}\right]$ serves to identify the block of the covariance matrix that corresponds to $x, J_{0}^{*}=\left[\begin{array}{ll}1 & 0\end{array}\right]$ is used to select the block corresponding to the variable $y$ in the covariance matrix $\Sigma_{0}^{*}(h)$. Finally, $G=\left[\begin{array}{lll}1 & 0 & 0 \\ 0 & 1 & 0\end{array}\right]$.

Equivalently, the total dependence can be derived as the sum of (i) causality from $x$ to $y$ (Policy $\rightarrow$ Risk), (ii) causality from $y$ to $x$ (Risk $\rightarrow$ Policy) and (iii) instantaneous causality between $x$ to $y$ (Policy $\leftrightarrow$ Risk):

$$
C(x \stackrel{h}{-} y \mid F)=C(y \stackrel{h}{\rightarrow} x \mid F)+C(x \stackrel{h}{\rightarrow} y \mid F)+C(x \stackrel{h}{\longleftrightarrow} y \mid F),
$$

where the instantaneous causality at horizon $h$ is quantified by the following formula:

$$
C(x \stackrel{h}{\longleftrightarrow} y \mid F)=\ln \left[\frac{\operatorname{det}\left[J_{1} \Sigma(h) J_{1}^{\prime}\right] \quad \operatorname{det}\left[J_{1}^{*} \Sigma(h)(h) J_{1}^{*^{\prime}}\right]}{\operatorname{det}[G \hat{\Sigma}(h) G]}\right]
$$

By definition, and as in the original measure proposed by Geweke (1982), measures of instantaneous causality rely on (potential) differences in covariances.

The causality measures that we focus on in the article are expressed as a percentage of the total dependence, such as $C(y \stackrel{h}{\rightarrow} x \mid F) / C\left(x-\frac{h}{-} y \mid F\right)$ and $C(x \stackrel{h}{\rightarrow} y \mid F) / C(x-y \mid F)$. 


\section{A2: Details on estimations}

This appendix details the 4-step procedure that we implement to estimate the causality measures and to gauge their statistical significance.

Step 1. Model estimation. We estimate a $\operatorname{VAR}(\mathrm{p})$ model with three variables, $x, y$ and $z$. The identification of the optimal lag $(p)$ in equation (1) relies on the Akaike information criterion (AIC) (Ivanov and Kilian, 2005; Kilian, 2001). Parameters $\Phi_{i}$, or equivalently $A$ in equation (4), and the covariance matrix of the residuals $\Sigma_{\varepsilon}$ are estimated by the ordinary least square method. Estimators are denoted by $\widehat{\Phi}, \widehat{A}$ and $\widehat{\Sigma}_{\varepsilon}$, respectively. Sims et al. (1990) demonstrate that OLS estimators for models in level remain consistent even in case of unit roots in the VAR system and cointegration between variables. Moreover, results are easier to interpret in level. The same order $p$ and the same estimation procedure is used for the two constrained models to determine $\widehat{\Sigma}_{0}$ and $\widehat{\Sigma}_{0}^{\star}$.

Step 2. Estimation of the forecast errors' covariance matrix at horizon $h$. Given $\widehat{A}$ and $\widehat{\Sigma}_{\varepsilon}$, and following equation (4), we compute an estimator for the covariance matrix of $h$-step ahead forecast errors $\widehat{\Sigma}(h)$. The same method prevails for the unconstrained models, to compute $\widehat{\Sigma}_{0}(h)$ and $\widehat{\Sigma}_{0}^{\star}(h)$.

Step 3. Computing causality measures. Given $\widehat{\Sigma}(h), \widehat{\Sigma}_{0}(h)$ and $\widehat{\Sigma}_{0}^{\star}(h)$, we compute an estimation for the causality measures defined by equations (5), (6) and (9), namely $\widehat{C}(y \stackrel{h}{\rightarrow} x \mid F)$, $\widehat{C}(x \stackrel{h}{\rightarrow} y \mid F)$ and $\widehat{C}(x \stackrel{h}{\rightarrow} y \mid F)$, respectively, for any horizon $h$. Under usual regularity assumptions that can be found in Lewis and Reinsel (1985) or Dufour and Taamouti (2010), these estimators are weakly consistent.

Step 4. Confidence intervals. To gauge the significance of our causality measures, the last step consists in building confidence intervals. We proceed by bootstrap-after-bootstrap as proposed by Kilian (1998), which allows us to correct for small-sample bias and skewness. Not applying this correction may lead to changes in the interval width and location, even if the bias is small. Additionally, this method can successfully be applied not only to stationary VARs, but also to random walk processes and cointegrated processes estimated in levels.

In the first round of bootstrap, the purpose is to compute the bias in the VAR coefficients. 
For this, we generate, based on the residuals obtained in Step 2, new bootstrap data for the dependent variable of the unconstrained model:

$$
W_{t}^{*}=\sum_{j=1}^{p} \hat{\Phi}_{j} W_{t-j}^{*}+\varepsilon_{t}^{*},
$$

where $\varepsilon_{t}^{*}$ is a random draw with replacement from $\left\{\hat{\varepsilon}_{t}\right\}_{t=p+1}^{T}$, with $T$ the sample size. OLS estimates are used to determine bootstrap coefficients, $\hat{\Phi}^{*}$. We repeat this procedure $B$ times, where $B$, the number of bootstrap samples, is equal to 999 , such that $\frac{1}{2} \alpha(B+1)$ is an integer (Davidson and MacKinnon, 2004), with $1-\alpha$ the confidence level. The bias of the VAR coefficients is given by Bias ${ }^{*}=\mathrm{E}\left[\hat{\Phi}^{*}-\hat{\Phi}\right]$. The bias estimate is $\widehat{\operatorname{Bias}}^{*}=\frac{1}{B} \sum_{j=1}^{B} \hat{\Phi}^{*}(j)-\hat{\Phi}$. At this stage, one should determine whether the VAR model is stationary or not. This can be done based on the absolute value of the largest root of the companion matrix associated with $\hat{\Phi}$. If this value is larger than one, no correction is needed for coefficients. If the value is less than one, bias-corrected coefficients, $\hat{\Phi}-\widehat{\operatorname{Bias}}^{*}$, should be used from this point on.

The second round of bootstrap concerns the computation of confidence intervals based on bootstrapped causality measures. Firstly, the bias-corrected coefficients are imposed in equation (10) and $B$ new bootstrap replications of $\widehat{W}_{t}$ are generated. Afterwards, the obtained model is estimated through OLS. The same bias from the first round of bootstrap is used to correct the estimated coefficients. The residuals from this model are used to determine the covariance matrix based on which long-run causality measures are computed. Using the same bootstrap sample, OLS regressions are used to estimate the two constrained models, where these coefficients also need to be bias-corrected (i.e., the two rounds of bootstrap are applied to the constrained models). Causality measures as defined by equations (5), (6), (9) and (8) are next computed. Finally, $\alpha$ and $1-\alpha$ percentile intervals are calculated for each of the four types of long run causality measures. 


\section{B. Data description}

Figure 6: Monetary policy stance and systemic risk (SRisk)

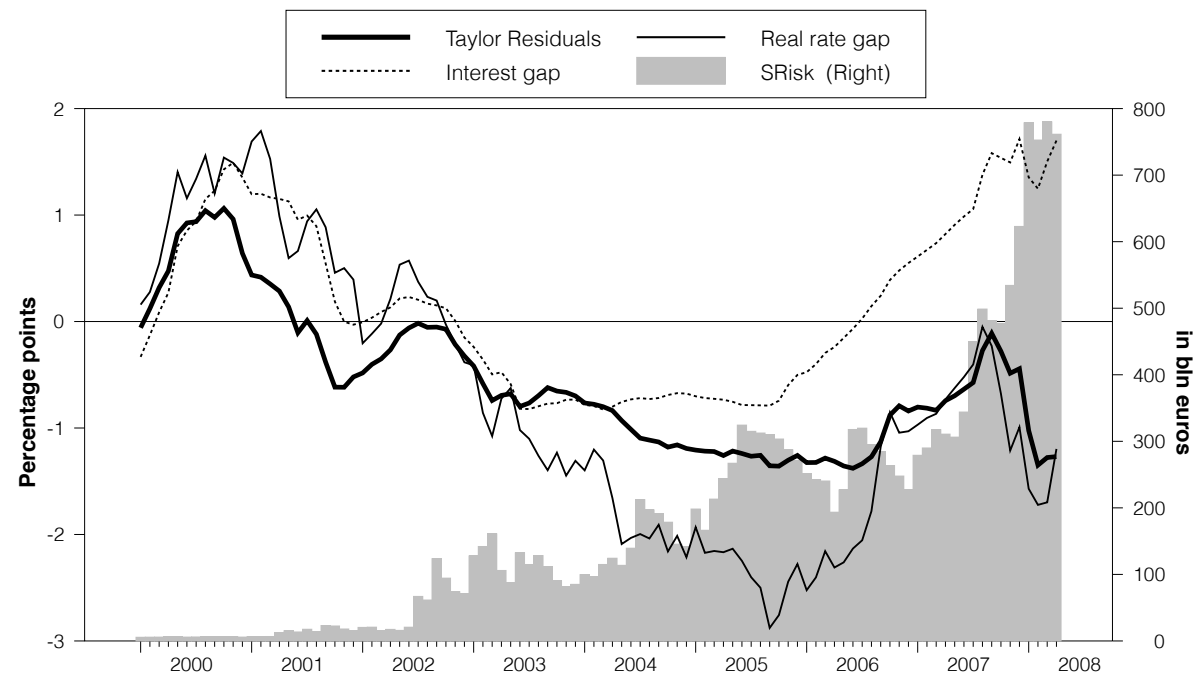

Note: This figure presents the evolution of three of the monetary policy stance variables as well as the dynamics of SRisk over the period 2000M1 - 2008M4. Taylor residuals are computed as the difference between the actual interest rate and a Taylor-type rule, $i_{t}^{*}=0.9 i_{t-1}^{*}+0.1\left\{r r_{t}^{*}+\bar{\pi}+\beta_{\pi}\left(\pi_{t}-\bar{\pi}\right)+\beta_{y} \tilde{y}_{t}\right\}$. Interest gap represents the short-term nominal interest rate gap with respect to its Hodrick-Prescott HP trend. The real rate gap is the difference between the real interest rate and its equilibrium value. SRisk measures systemic risk in the euro area.

Figure 7: Credit-to-gdp gap and Srisk for the banking sector (SRisk_bk)

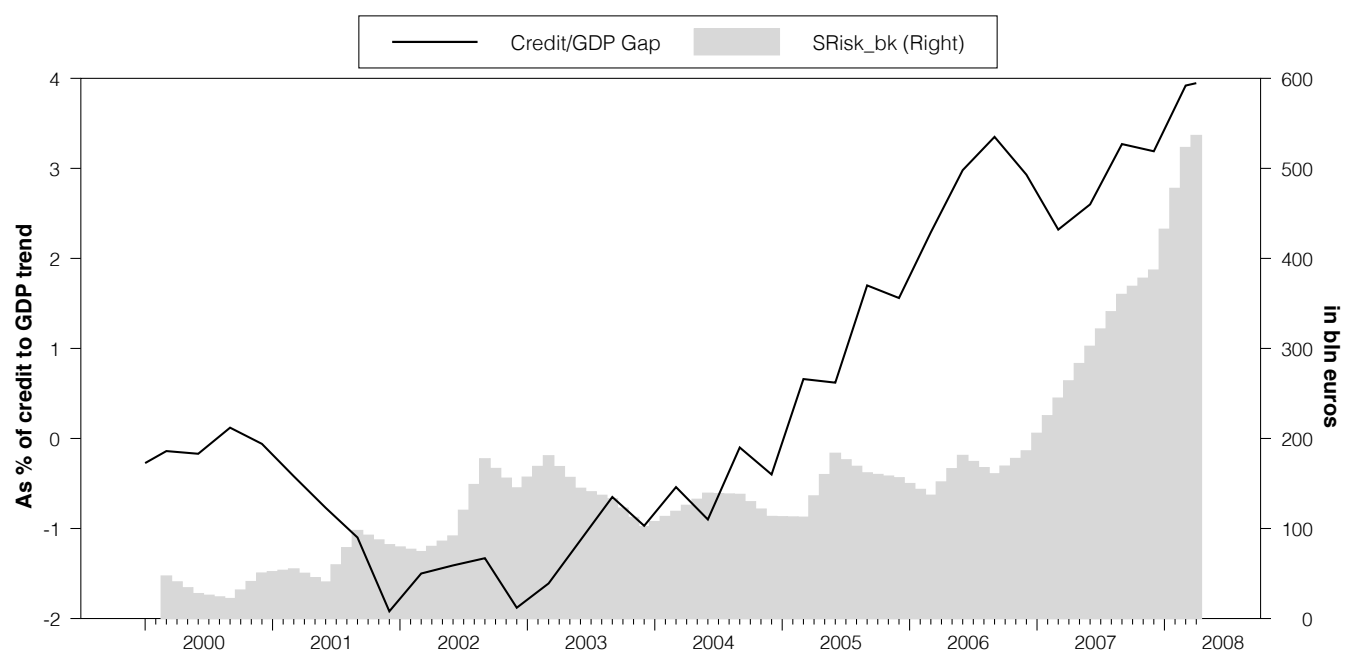

Note: This figure presents the dynamics of the of the credit-to-GDP gap with respect to its HP trend as well as the evolution of the aggregate SRisk for the sole banking sector, labeled SRisk_bk, i.e. the SRisk excluding insurance companies, financial services and real estate firms. 
Table 2: Description of auxiliary variables, $z$

\begin{tabular}{|c|c|c|}
\hline Group & Variable description & Source \\
\hline \multirow[t]{2}{*}{ Global risk perception } & $\begin{array}{l}\text { The VSTOXX Index is based on EURO } \\
\text { STOXX } 50 \text { real time options prices and is } \\
\text { designed to reflect market expectations of } \\
\text { volatility. }\end{array}$ & Datastream \\
\hline & Global Risk Aversion Indicator & ECB SDW \\
\hline \multirow{5}{*}{ Perception of firms' riskiness } & $\begin{array}{l}\text { The risk premium computed as the difference } \\
\text { between the bank lending rate and the short } \\
\text { term interest rate. }\end{array}$ & Datastream \\
\hline & $\begin{array}{l}\text { The spread between the BofA Merrill Lynch } \\
\text { BBB Euro Non-Financial Index and the 10- } \\
\text { year German government bond yield. The } \\
\text { BBB index is computed based on the cost } \\
\text { of bonds issued by firms with an investment } \\
\text { grade BBB. }\end{array}$ & Datastream \\
\hline & Stock market index for the Eurozone & Datastream \\
\hline & $\begin{array}{l}\text { Expected default frequency of non financial } \\
\text { corporations }\end{array}$ & Moody's \\
\hline & The cost of equity for firms & ECB SDW \\
\hline \multirow{3}{*}{ Perception of banks' riskiness } & Expected default frequency for banks & Moody's \\
\hline & Cost of equity for banks & ECB SDW \\
\hline & Capital-to-asset ratio & ECB SDW \\
\hline
\end{tabular}

Note: ECB SDW = ECB Statistical Data Warehouse. All variables have a monthly frequency. 
Figure 8: Evolution of auxiliary variables $z$

VSTOXX

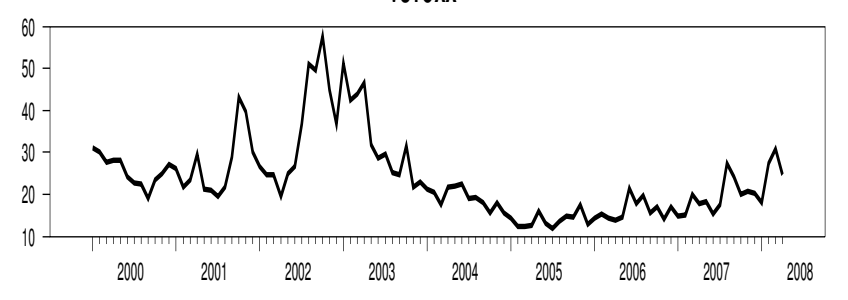

GRAl
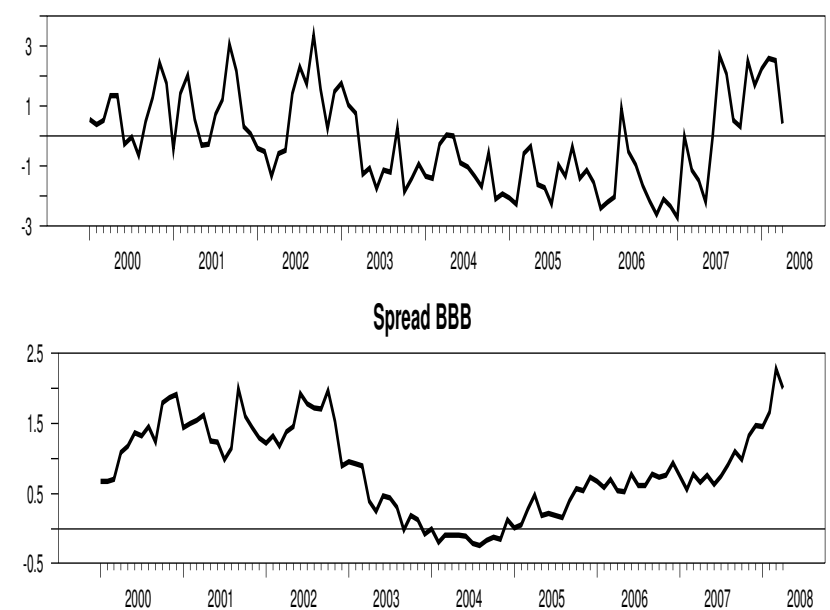

Stock return index
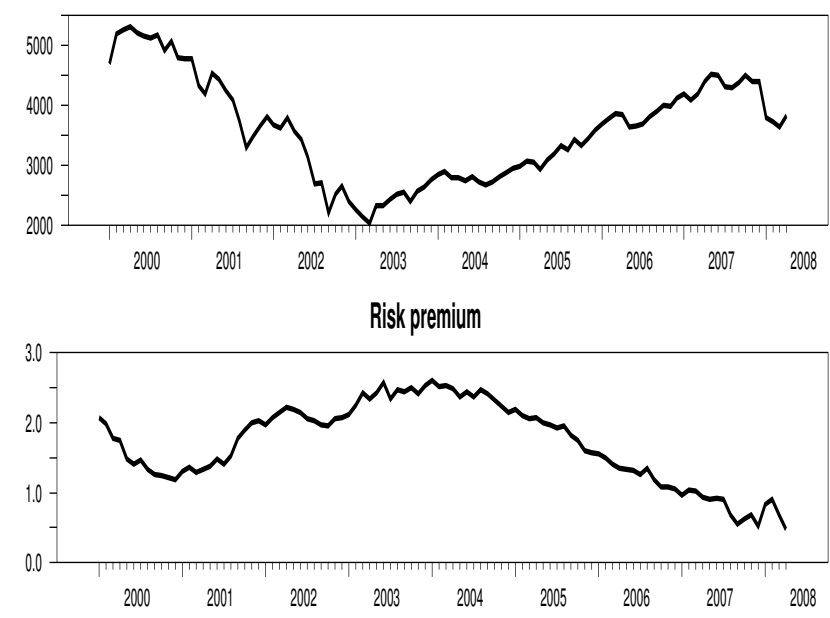

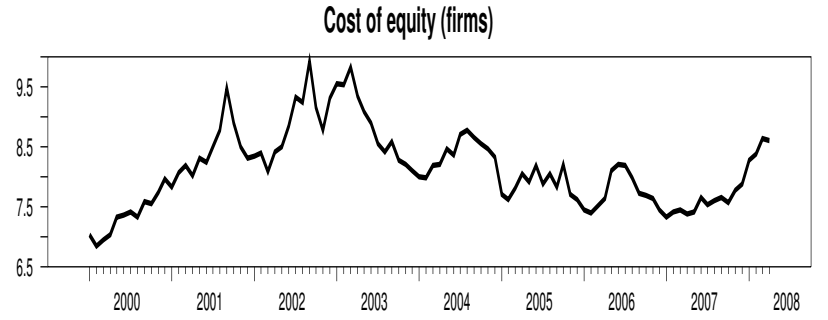

EDF firms
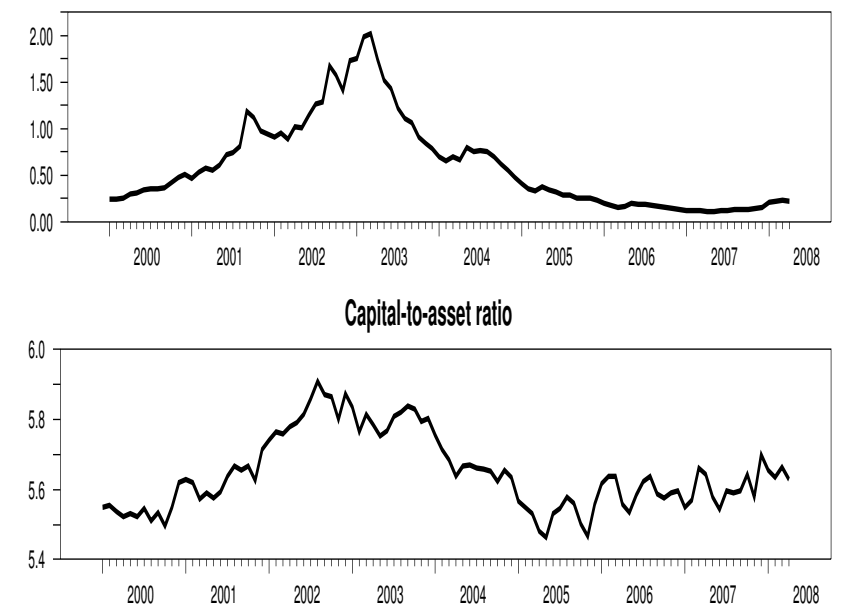

Cost of equity (banks)

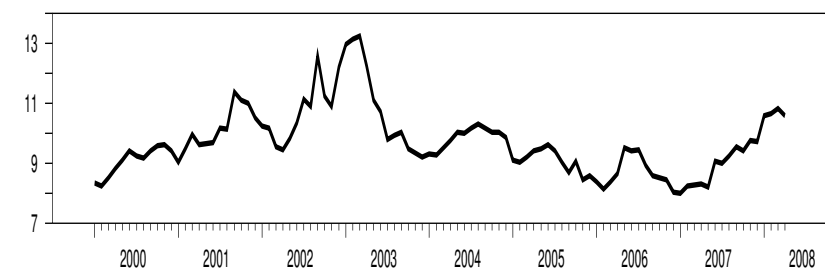

EDF banks

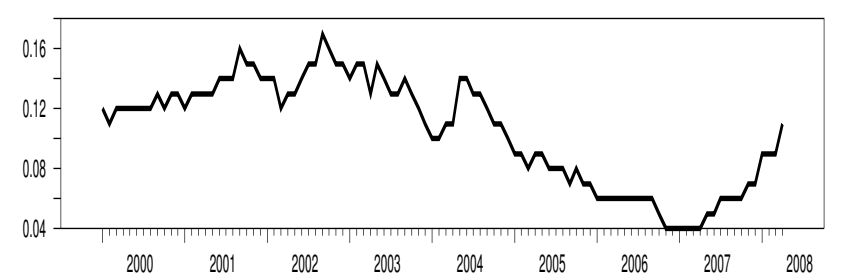

Note: This figure presents the evolution of all auxiliary variables employed in the main analysis, over the period 2000M1 - 2008M4. Source: See Table 2. 


\section{Results - Figures}

Figure 9: Causality measures for $\mathrm{z}=$ Risk premium
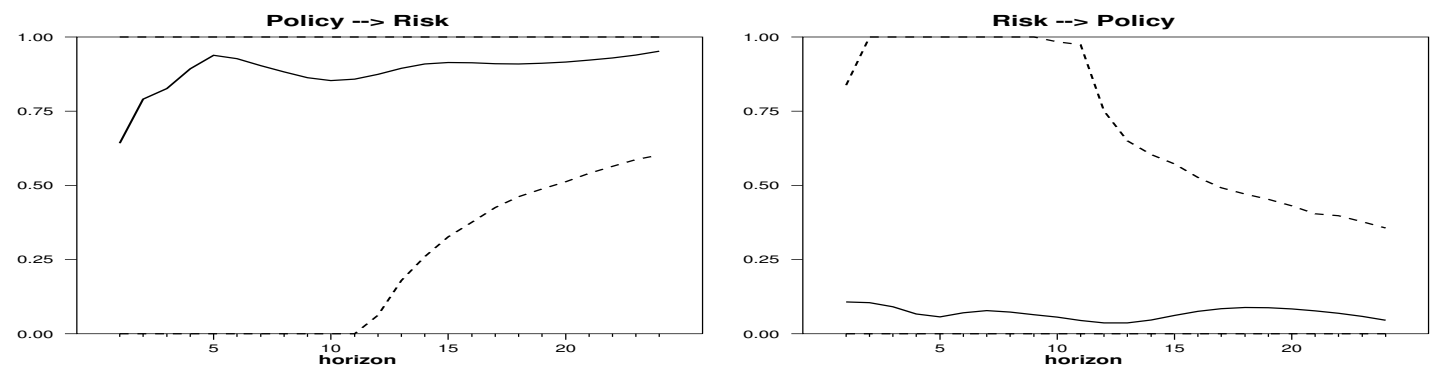

Note: This figure presents causality measures for the variables $x$ (Policy) and $y$ (Risk). More precisely, $\mathrm{x}=$ Taylor residuals and $\mathrm{y}$ $=$ SRisk. The auxiliary variable is the Risk premium. The order of the VAR, selected by AIC, is 4 . Confidence intervals at $95 \%$ are represented by the dashed lines.

Figure 10: Causality measures for $\mathrm{z}=$ Stock market index
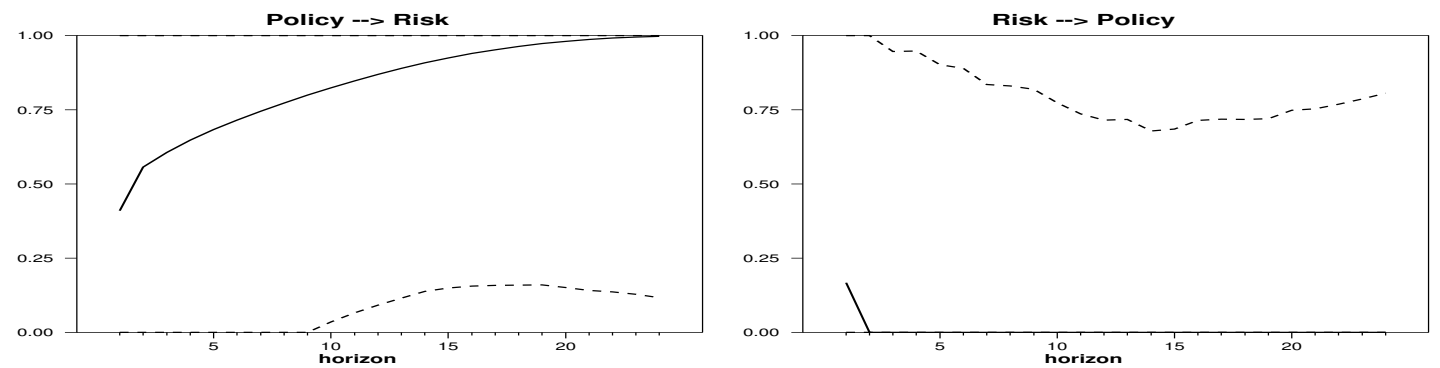

Note: This figure presents causality measures for the variables $x$ (Policy) and $y$ (Risk). More precisely, $\mathrm{x}=$ Taylor residuals and $\mathrm{y}$ $=$ SRisk. The auxiliary variable is the Stock market index. The order of the VAR, selected by AIC, is 1 . Confidence intervals at $95 \%$ are represented by the dashed lines.

Figure 11: Causality measures for $\mathrm{z}=$ Cost of equity (firms)
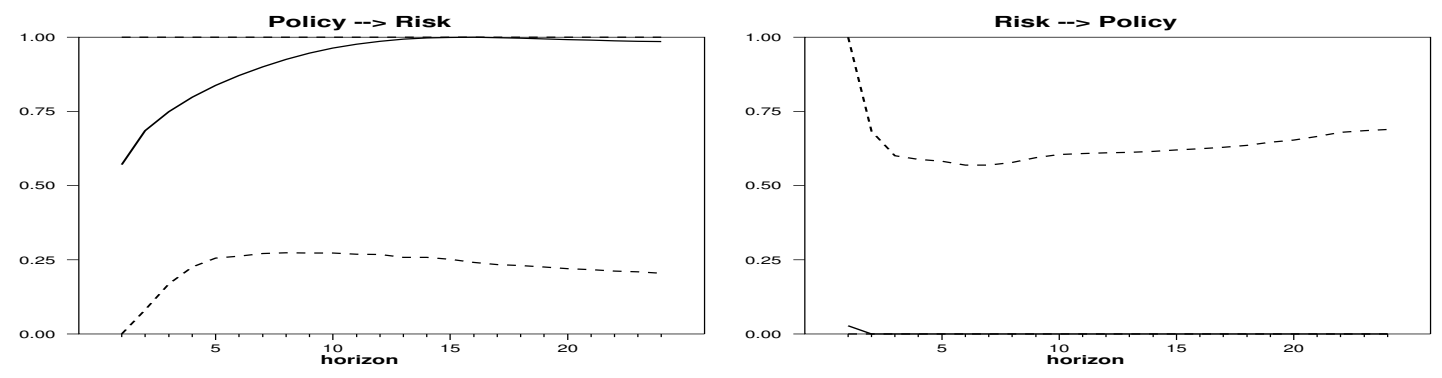

Note: This figure presents causality measures for the variables $x$ (Policy) and $y$ (Risk). More precisely, $\mathrm{x}=$ Taylor residuals and $\mathrm{y}$ $=$ SRisk. The auxiliary variable is the Cost of equity (firms). The order of the VAR, selected by AIC, is 1 . Confidence intervals at $95 \%$ are represented by the dashed lines. 
Figure 12: Causality measures for $\mathrm{z}=$ Expected default frequency (banks)
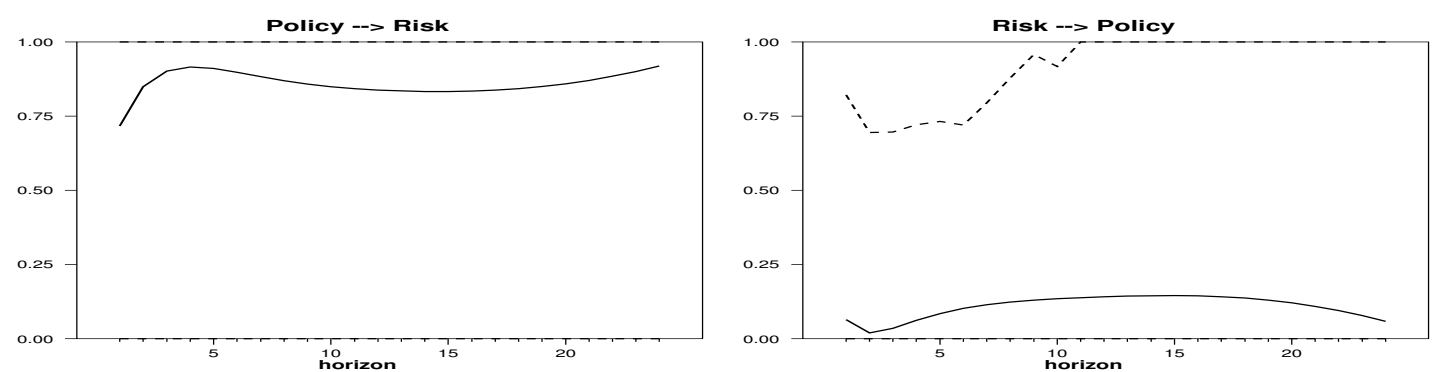

Note: This figure presents causality measures for the variables $x$ (Policy) and $y$ (Risk). More precisely, $\mathrm{x}=$ Taylor residuals and $\mathrm{y}=$ SRisk. The auxiliary variable is the Expected default frequency (banks). The order of the VAR, selected by AIC, is 2 . Confidence intervals at $95 \%$ are represented by the dashed lines.

Figure 13: Causality measures for $\mathrm{z}=$ Cost of equity (banks)
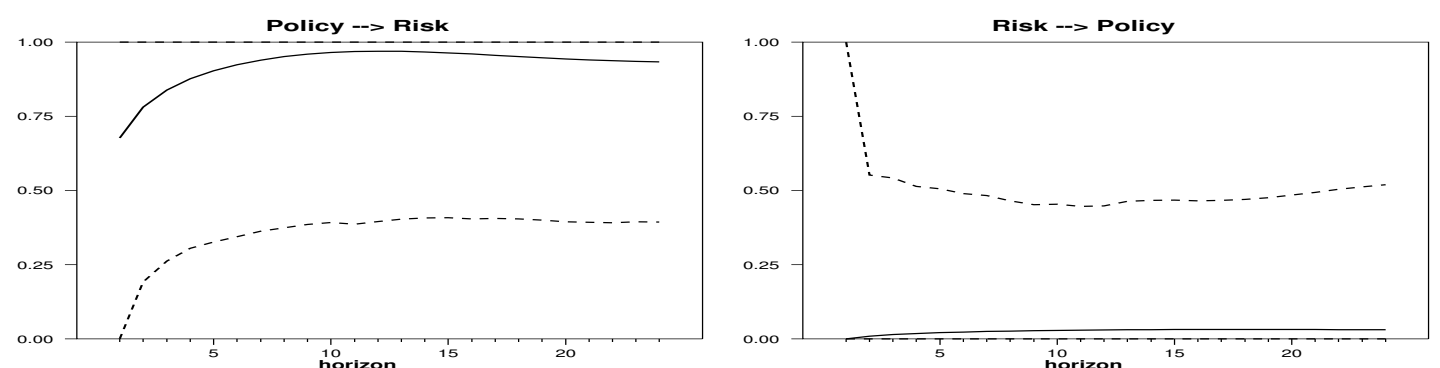

Note: This figure presents causality measures for the variables $x$ (Policy) and $y$ (Risk). More precisely, $\mathrm{x}=$ Taylor residuals and $\mathrm{y}$ $=$ SRisk. The auxiliary variable is the Cost of equity (banks). The order of the VAR, selected by AIC, is 1 . Confidence intervals at $95 \%$ are represented by the dashed lines. 


\section{Robustness - Figures}

\section{Robustness to $x$}

Table 3: Causality measures with alternative monetary policy stance measures and auxiliary variables related to the global risk perception

\begin{tabular}{|l|cc|cc|}
\hline & \multicolumn{2}{|c|}{ VSTOXX } & \multicolumn{2}{c|}{ GRAI } \\
& Policy $\rightarrow$ Risk & Risk $\rightarrow$ Policy & Policy $\rightarrow$ Risk & Risk $\rightarrow$ Policy \\
\hline Taylor residuals (2) & Yes (13-) & No & Yes $(4-)$ & No \\
Taylor residuals (3) & Yes (15-) & Yes $(1)$ & Yes $(13-)$ & No \\
Taylor residuals (4) & No & No & No & No \\
Taylor residuals (5) & Yes $(1-5,10-)$ & No & Yes $(1-8,13-)$ & No \\
Interest gap & Yes $(2-20)$ & No & Yes $(3-15)$ & No \\
Real rate gap & Yes $(1-)$ & No & Yes (5-7) & No \\
\hline
\end{tabular}

Note: "Yes" means that causality measures are significant. In parenthesis, the interval represents the periods during which the measure is significant. If there is only one number, it means that the measure stays significant until the end of our horizon, $\mathrm{h}=24$. "No" indicates that causality measures are not significant

Table 4: Causality measures with alternative monetary policy stance measures and auxiliary variables related to the perception of firms' riskiness (1)

\begin{tabular}{|c|c|c|c|c|c|c|}
\hline & \multicolumn{2}{|c|}{ BBB spread } & \multicolumn{2}{|c|}{ Risk premium } & \multicolumn{2}{|c|}{ Stock market index } \\
\hline & Policy $\rightarrow$ Risk & Risk $\rightarrow$ Policy & Policy $\rightarrow$ Risk & Risk $\rightarrow$ Policy & Policy $\rightarrow$ Risk & Risk $\rightarrow$ Policy \\
\hline Taylor residuals (2) & Yes $(12-)$ & No & Yes $(14-)$ & No & Yes $(13-)$ & No \\
\hline Taylor residuals (3) & Yes $(14-)$ & Yes $(2-3)$ & Yes $(19-)$ & No & No & Yes (1) \\
\hline Taylor residuals (4) & Yes $(6-)$ & No & Yes $(24)$ & No & No & No \\
\hline Taylor residuals (5) & Yes $(1-)$ & No & Yes $(1-)$ & No & Yes $(1-)$ & No \\
\hline Interest gap & Yes $(3-)$ & No & Yes $(1-7)$ & No & No & No \\
\hline Real rate gap & Yes $(2-)$ & No & Yes (12 - ) & No & No & No \\
\hline
\end{tabular}

Note: "Yes" means that causality measures are significant. In parenthesis, the interval represents the periods during which the measure is significant. If there is only one number, it means that the measure stays significant until the end of our horizon, $\mathrm{h}=24$. "No" indicates that causality measures are not significant 
Table 5: Causality measures with alternative monetary policy stance measures and auxiliary variables related to the perception of firms' riskiness (2)

\begin{tabular}{|l|cc|cc|}
\hline & \multicolumn{2}{|c|}{ Expected default frequency (firms) } & \multicolumn{2}{c|}{ Cost of equity (firms) } \\
& Policy $\rightarrow$ Risk & Risk $\rightarrow$ Policy & Policy $\rightarrow$ Risk & Risk $\rightarrow$ Policy \\
\hline Taylor residuals (2) & Yes $(9-)$ & No & Yes $(14-)$ & No \\
Taylor residuals (3) & No & Yes $(1-3)$ & No & Yes $(1)$ \\
Taylor residuals (4) & No & No & Yes $(8-16)$ & No \\
Taylor residuals (5) & Yes $(1-4,11-)$ & No & Yes $(1-)$ & No \\
Interest gap & Yes $(2-)$ & No & Yes $(3-)$ & No \\
Real rate gap & Yes $(2-)$ & No & Yes $(1-)$ & No \\
\hline
\end{tabular}

Note: "Yes" means that causality measures are significant. In parenthesis, the interval represents the periods during which the measure is significant. If there is only one number, it means that the measure stays significant until the end of our horizon, h=24. "No" indicates that causality measures are not significant

Table 6: Causality measures with alternative monetary policy stance measures and auxiliary variables related to the perception of banks' riskiness

\begin{tabular}{|l|cc|cc|c|}
\hline & \multicolumn{2}{|c|}{ Expected default frequency (banks) } & \multicolumn{2}{c|}{ Cost of equity (banks) } & \multicolumn{2}{c|}{ Capital-to-asset ratio } \\
& Policy $\rightarrow$ Risk & Risk $\rightarrow$ Policy & Policy $\rightarrow$ Risk & Risk $\rightarrow$ Policy & Policy $\rightarrow$ Risk Risk $\rightarrow$ Policy \\
\hline Taylor residuals (2) & Yes $(10-)$ & No & Yes $(10-)$ & No & Yes $(10-)$ \\
Taylor residuals (3) & Yes $(15-)$ & Yes $(1-2)$ & Yes $(15-)$ & Yes $(1)$ & Yes $(17-)$ \\
Taylor residuals (4) & Yes $(1-)$ & No & Yes $(1-10)$ & No & Yes $(1-10)$ \\
Taylor residuals (5) & Yes $(2-)$ & No & No & No & Yes $(1-)$ \\
Interest gap & Yes $(7-)$ & No & Yes $(1-)$ & No & Yes $(1-20)$ \\
Real rate gap & Yes $(3-)$ & No & Yes $(2-)$ & No & Yes $(1-)$ \\
\hline
\end{tabular}

Note: "Yes" means that causality measures are significant. In parenthesis, the interval represents the periods during which the measure is significant. If there is only one number, it means that the measure stays significant until the end of our horizon, h=24. "No" indicates that causality measures are not significant

\section{Robustness to control variables}

Table 7: Causality measures with control variables, $\mathrm{x}=$ Taylor residuals and $\mathrm{y}=$ SRisk (1)

\begin{tabular}{|l|cc|cc|}
\hline & \multicolumn{2}{|c|}{ VSTOXX } & \multicolumn{2}{c|}{ GRAI } \\
& Policy $\rightarrow$ Risk & Risk $\rightarrow$ Policy & Policy $\rightarrow$ Risk & Risk $\rightarrow$ Policy \\
\hline Unemployment & Yes $(2-)$ & No & No & No \\
Fed funds & Yes $(1-)$ & No & Yes $(2-)$ & No \\
Exchange rate & Yes $(4-)$ & No & No & No \\
Expected growth rate & Yes $(2-)$ & No & Yes $(2-)$ & No \\
\hline
\end{tabular}

Note: "Yes" means that causality measures are significant. In parenthesis, the interval represents the periods during which the measure is significant. If there is only one number, it means that the measure stays significant until the end of our horizon, $\mathrm{h}=24$. "No" indicates that causality measures are not significant 
Table 8: Causality measures with control variables, $\mathrm{x}=$ Taylor residuals and $\mathrm{y}=$ SRisk $(2)$

\begin{tabular}{|l|cc|cc|cc|}
\hline & \multicolumn{2}{|c|}{ BBB spread } & \multicolumn{2}{c|}{ Risk premium } & \multicolumn{2}{c|}{ Stock market index } \\
& Policy $\rightarrow$ Risk & Risk $\rightarrow$ Policy & Policy $\rightarrow$ Risk & Risk $\rightarrow$ Policy & Policy $\rightarrow$ Risk Risk $\rightarrow$ Policy \\
\hline Unemployment & Yes (1-) & No & No & No & Yes $(3-)$ & No \\
Fed funds & Yes $(5-)$ & No & Yes $(7-)$ & No & Yes $(3-)$ & No \\
Exchange rate & Yes $(6-)$ & No & Yes $(17-)$ & No & Yes $(6-)$ & No \\
Expected growth rate & Yes $(5-)$ & No & Yes $(9-)$ & No & Yes $(2-)$ & No \\
\hline
\end{tabular}

Note: "Yes" means that causality measures are significant. In parenthesis, the interval represents the periods during which the measure is significant. If there is only one number, it means that the measure stays significant until the end of our horizon, $\mathrm{h}=24$. "No" indicates that causality measures are not significant

Table 9: Causality measures with control variables, $\mathrm{x}=$ Taylor residuals and $\mathrm{y}=$ SRisk (3)

\begin{tabular}{|l|cc|cc|}
\hline & Expected default frequency (firms) & \multicolumn{2}{c|}{ Cost of equity (firms) } \\
& Policy $\rightarrow$ Risk & Risk $\rightarrow$ Policy & Policy $\rightarrow$ Risk & Risk $\rightarrow$ Policy \\
\hline Unemployment & Yes $(2-)$ & No & Yes $(5-10)$ & No \\
Fed funds & Yes $(1-)$ & No & Yes $(1-)$ & No \\
Exchange rate & Yes $(3-)$ & No & Yes $(4-)$ & No \\
Expected growth rate & Yes $(2-)$ & No & Yes $(1-)$ & No \\
\hline
\end{tabular}

Note: "Yes" means that causality measures are significant. In parenthesis, the interval represents the periods during which the measure is significant. If there is only one number, it means that the measure stays significant until the end of our horizon, $\mathrm{h}=24$. "No" indicates that causality measures are not significant

Table 10: Causality measures with control variables, $\mathrm{x}=$ Taylor residuals and $\mathrm{y}=$ SRisk (4)

\begin{tabular}{|l|cc|cc|cc|}
\hline & \multicolumn{2}{|c|}{ Expected default frequency (banks) } & \multicolumn{2}{c|}{ Cost of equity (banks) } & \multicolumn{2}{c|}{ Capital-to-asset ratio } \\
& Policy $\rightarrow$ Risk & Risk $\rightarrow$ Policy & Policy $\rightarrow$ Risk & Risk $\rightarrow$ Policy & Policy $\rightarrow$ Risk Risk $\rightarrow$ Policy \\
\hline Unemployment & Yes $(2-)$ & No & Yes $(2-)$ & No & Yes $(7-)$ & No \\
Fed funds & Yes $(2-)$ & No & Yes $(1-)$ & No & Yes $(1-)$ & No \\
Exchange rate & Yes $(6-)$ & No & Yes $(2-)$ & No & Yes $(6-)$ & No \\
Expected growth rate & Yes $(2-)$ & No & Yes $(1-)$ & No & Yes $(1-)$ & No \\
\hline
\end{tabular}

Note: "Yes" means that causality measures are significant. In parenthesis, the interval represents the periods during which the measure is significant. If there is only one number, it means that the measure stays significant until the end of our horizon, $\mathrm{h}=24$. "No" indicates that causality measures are not significant 


\section{Robustness to $y$}

Table 11: Causality measures with alternative systemic risk measures $y$

\begin{tabular}{|c|c|c|c|c|}
\hline & \multicolumn{2}{|c|}{ SRisk banks } & \multicolumn{2}{|c|}{ Credit-to-GPD gap } \\
\hline & Policy $\rightarrow$ Risk & Risk $\rightarrow$ Policy & Policy $\rightarrow$ Risk & Risk $\rightarrow$ Policy \\
\hline VSTOXX & Yes $(5-)$ & No & Yes $(11-19)$ & No \\
\hline GRAI & Yes $(2-)$ & No & No & No \\
\hline BBB spread & Yes $(4-)$ & No & No & No \\
\hline Risk premium & Yes $(5-)$ & No & Yes $(11-14)$ & No \\
\hline Stock market index & Yes $(7-)$ & No & Yes $(9-)$ & No \\
\hline Expected default frequency (firms) & Yes $(6-)$ & No & Yes $(7-24)$ & No \\
\hline Cost of equity (firms) & Yes $(5-)$ & No & Yes $(4-23)$ & No \\
\hline Expected default frequency (banks) & No & No & No & No \\
\hline Cost of equity (banks) & Yes $(6-)$ & No & No & No \\
\hline Capital-to-asset ratio & Yes $(1-)$ & No & Yes $(4-15)$ & No \\
\hline
\end{tabular}

$\mathrm{x}=$ Taylor residuals. Note: "Yes" means that causality measures are significant. In parenthesis, the interval represents the periods during which the measure is significant. If there is only one number, it means that the measure stays significant until the end of our horizon, $\mathrm{h}=24$. "No" indicates that causality measures are not significant 